\title{
How do maternal HIV infection and the early nutritional environment influence the development of infants exposed to HIV in utero?
}

\author{
Marina White ${ }^{\mathrm{a}}$, Eleanor Duffley ${ }^{\mathrm{a}}$, Ute D. Feucht ${ }^{\mathrm{b}, \mathrm{c}, \mathrm{d}}$, Theresa Rossouw ${ }^{\mathrm{e}}$, Kristin L. Connor ${ }^{\mathrm{a}, 1}$ \\ ${ }^{\text {a }}$ Department of Health Sciences, Carleton University, Ottawa, ON K1S 5B6, Canada \\ ${ }^{\mathrm{b}}$ Paediatrics, University of Pretoria, Pretoria, GP 0002, South Africa \\ ${ }^{\mathrm{c}}$ Research Centre for Maternal, Fetal, Newborn \& Child Health Care Strategies, University of Pretoria, Pretoria, GP 0002, South \\ Africa \\ ${ }^{\mathrm{d}}$ Maternal and Infant Health Care Strategies Unit, South African Medical Council, Pretoria, GP 0002, South Africa \\ e Institute for Cellular and Molecular Medicine, Department of Immunology, University of Pretoria, Pretoria, GP 0002, South \\ Africa \\ ${ }^{1}$ Correspondence: kristin.connor@carleton.ca (KLC); Tel.: +1 613-520-2600 ext. 420
}

\begin{abstract}
Malnutrition and infectious disease often coexist in socially inequitable contexts. Malnutrition in the perinatal period adversely affects offspring development and lifelong non-communicable disease risk. Less is known about the effects of infectious disease exposure during critical windows of development and health, and links between in utero HIV-exposure in the absence of neonatal infection, perinatal nutritional environments, and infant development are poorly defined. In a pilot feasibility study at Kalafong Hospital, Pretoria, South Africa, we aimed to better understand relationships between maternal HIV infection and the early nutritional environment of in utero HIV exposed uninfected (HEU) infants. We also undertook exploratory analyses to investigate relationships between food insecurity and infant development. Mother-infant dyads were recruited after delivery and followed until 12 weeks postpartum. Household food insecurity, nutrient intakes and dietary diversity scores did not differ between mothers living with or without HIV. Maternal reports of food insecurity were associated with lower maternal nutrient intakes 12 weeks postpartum, and in infants, higher brain-to-body weight ratio at birth and 12 weeks of age, and attainment of fewer large movement and play activities milestones at 12 weeks of age, irrespective of maternal HIV status. Reports of worry about food runout were associated with increased risk of stunting for HEU, but not unexposed, uninfected infants. Our findings suggest that food insecurity, in a vulnerable population, adversely affects maternal nutritional status and infant development. In utero exposure to HIV may further perpetuate these effects, which has implications for early child development and lifelong human capital.
\end{abstract}

Keywords: HIV, neurodevelopment, growth, nutrition, food security, breastfeeding, pregnancy

\section{Introduction}

Suboptimal nutrition and poor maternal metabolic health during pregnancy and in the postpartum period are known to impact fetal development, particularly of the brain [1,2], and infant health trajectories after birth [3]. In contrast, the effects of fetal exposure to maternal infectious diseases during critical windows of development on offspring growth, neurodevelopment, and lifelong health are less understood. HIV infection has profound effects on maternal physiology and pregnancy outcomes, including increased risk of preterm birth, low birth weight, and increased susceptibility to subsequent infections in infants [4,5]. HIVexposed, infected (HEI) infants show poorer motor, cognitive, language, and behavioural outcomes compared to controls as early as three months of age [6-9]. However, as global access to antiretroviral therapy (ART) for pregnant and breastfeeding women increases and mother-to-child HIV transmission declines [10], the population of HIV-exposed (in utero or during breastfeeding) but uninfected (HEU) infants continues to rise. Immune dysfunction, inflammation, metabolic abnormalities, and intestinal dysbiosis persist in HIV-infected individuals on ART, including pregnant women [11]. Some evidence suggests that HEU infants may have persistently altered motor and cognitive development [12-14], albeit to a lesser extent than HEI infants. However, the extent to which inflammatory and metabolic derangements in the mother shape development in their HEU infants remains poorly understood.

The developing brain is also vulnerable to the effects of suboptimal maternal nutrition, as the fetal and neonatal brain depend on nutrition supplied by the mother through transplacental transfer and through breastfeeding and other enteral feeds, to support periods of rapid growth during the perinatal period [15]. Malnutrition (under- or overnutrition) during critical periods of brain development alters neuroanatomical development (neuronal cell growth and proliferation, synapse development, and circuit formation), neurochemistry (synthesis of neurotransmitters, neurotransmitter receptors, and re-uptake mechanisms), and neurophysiology (neurometabolic alterations) [1]. The dependence of the developing brain on adequate nutrition during sensitive periods of its growth and development makes especially the developing fetus, and also the neonate, highly vulnerable to the effects of food and nutrition insecurity.

Interactions between exposure to infectious disease (such as HIV) and malnutrition (such as undernutrition and food insecurity), are important to consider, given that malnutrition and infectious diseases often coexist in socially inequitable contexts. Maternal immunosuppression related to 
HIV infection may be exacerbated by malnutrition [16], and the comorbidity of these exposures for infants in utero and during the breastfeeding period may be more detrimental than the occurrence of one of these circumstances alone. South Africa not only faces the greatest HIV burden globally, with $19 \%$ of the world's population who live with HIV residing in South Africa, but also reports comparable rates of malnutrition and food insecurity [17]. Understanding the extent to which in utero HIV exposure, without infant HIV infection, influences infant development is a public health priority [18], and due to the high rates of food and nutrition insecurity, it is therefore also critical to understand how the early nutritional environment interacts with infectious exposures to influence developmental trajectories in HEU infants.

We undertook a prospective cohort pilot feasibility study in Pretoria, South Africa, to determine if we could recruit women through our clinics to study the cooccurring effects of HIV exposure and maternal nutrition on growth and neurodevelopment in infants in early life, and to advance our knowledge on these exposure-outcome relationships. We hypothesised that mothers living with HIV would experience greater household food insecurity, and that maternal HIV infection would influence infant feeding patterns. We also undertook exploratory analyses to investigate overall household food security and diet quality in this cohort, hypothesising that food insecurity alone would be associated with infant feeding patterns, and infant growth and neurodevelopmental outcomes.

\section{Methods}

\section{Study population}

From the obstetric unit at Kalafong hospital, women living with and without HIV were recruited within four days of delivery (HIV infected: $n=32$, HIV uninfected: $\mathrm{n}=22$ ) and followed-up at 12 weeks (range 8-16 weeks) postpartum (HIV infected: $n=21$, HIV uninfected: $n=10$ ) at the Maternal and Infant Health Care Strategies Unit (MIHCSU) of the South African Medical Research Council. Study recruitment took place between June-December 2016, with all follow up data collected by March 2017. All infants exposed to HIV were tested for infection at birth and 12 weeks postpartum and were confirmed negative. This study was approved by the Research Ethics Committee of the Faculty of Health Sciences of the University of Pretoria (185-2016) and the Carleton University Research Ethics Board (108870).

\section{Recruitment and eligibility}

A research nurse recruited eligible women after delivery. Exclusion criteria included infant delivery by caesarean section, pregnancy complications (including gestational diabetes mellitus, multiple gestations), or antibiotic exposure during labour or delivery and/or the postpartum period. Women were also ineligible to participate if they were from other regions and would find it difficult to come back for follow-up.

\section{Data collection}

A retrospective medical chart review was conducted after delivery to extract antenatal data, including maternal characteristics (age at conception, ethnicity, parity, gravidity, smoking status, weight during pregnancy); medication use during pregnancy (including antibiotic exposure); illness/infections during pregnancy; and pregnancy outcomes (duration of gestation). At the postpartum follow up visit, mothers completed a questionnaire to assess breastfeeding practices, maternal lifestyle factors (including alcohol intake and smoking), and nutrition (including vitamin supplements, food security, and a 24-hour dietary recall). Where visits to clinics or hospitals occurred between birth and the follow up visit, the patientretained child health record (Road to Health Chart [19]) was examined to extract data on infant weight, history of illness and medication use.

\section{Primary outcome measures}

Primary outcomes of interest were anthropometry in infants at birth and 12 weeks, weight gain from birth to 12 weeks postpartum, Apgar scores at one and five minutes, and neurodevelopmental status (Guide for Monitoring Child Development [20]) in infants aged 12 weeks.

\section{Infant anthropometry}

Infant weight, length, and abdominal and head circumference and body mass index (BMI) were measured at birth and in infants aged 12 weeks. Infant anthropometry were age- and sex- standardised using World Health Organization (WHO) growth standards (WHO Anthro software v 3.2.2, January 2011) [21]. A brain weight estimate was calculated using an equation derived by the National Institute of Neurological and Communicative Disorders and Stroke's Collaborative Perinatal Project [22]:

$$
\text { brain weight }(g)=0.037 \times \text { head circumference }(\mathrm{cm})^{2.57}
$$

The brain weight estimate was used to calculate the infant brain-to-body weight ratio $(\mathrm{BBR})[23]$ :

$$
B B R=100 \times \text { (brain weight estimate }[g]) /(\text { birth weight }[g])
$$

$\mathrm{BBR}$ is used as a measure of potential in utero asymmetric intrauterine growth restriction (IUGR) and brain sparing [23]. Weight gain from birth to 12 weeks postnatal age (kg/day) was calculated using the weight of an infant at birth and follow up, and the days alive since birth at follow up:

$$
\text { Weight gain }\left(\frac{\mathrm{kg}}{\mathrm{day}}\right)=\frac{\text { infant weight }(12 \text { wks }[\mathrm{kg}])-\text { birthweight }(\mathrm{kg})}{\text { number of days alive }}
$$

\section{Infant neurodevelopment}

The Guide for Monitoring Child Development (GMCD) [20] was developed, standardised and validated [24] for use in low- and middle-income countries, including South Africa, to assess expressive and receptive language, play activities, relating and response behaviour, and fine and large movement in infants 1 to 24 months postpartum. An assessment for each infant was carried out once between 8 and 16 weeks postpartum by trained staff at the MIHCSU, which involved the researcher asking the child's caregiver a series of open-ended questions relating to the child's development. The GMCD monitors infants who are 1-3 months of age (defined as 1 month to 2 months and 30 days) for achievement milestones listed in the 1-3 month category, and infants who are 3-5 months ( 3 months +1 day to 4 months +30 days) for achievement of all milestones up to 3-5 months. Infants who were premature $(<37$ weeks) were assessed according to corrected gestational age. GMCD outcomes were quantified in 2 ways. First, the total number of 1-4 month GMCD milestones attained by each infant, regardless of whether the infant fell was 1-3 or 3-5 months of age at follow up, was quantified for expressive and receptive language, play activities, relating and response behaviour, and fine and large movement. Next, the proportion of infants having attained all milestones in their age category (1-3 months, or 3-5 months) for expressive and receptive language, fine and large movement, play activities and relating/response behaviour, compared to the proportion that had not attained all milestones, was quantified.

\section{Secondary exposure and outcome measures}

\section{Maternal food security and dietary recall}

A questionnaire was developed to collect maternal reports of food security. Mothers were asked if, in the past 12 months, 1. They and other household members worried that food would run out before they got money to buy more (often true, sometimes true, or never true), 2. The food that they and other household members bought just didn't last, and there wasn't any money to get more (often true, sometimes true, or never true), and 3. They and other household members couldn't afford to eat balanced meals (often true, sometimes true, or never true). Due to our small sample size, maternal reports of 'often true' and 'sometimes true' were grouped together for analyses as 'experiences food insecurity' and compared with 'never true' responses.

Maternal dietary recall data collected detailed all food and drink consumed in the day prior to the follow up appointment. Dietary recall data were analysed using FoodFinder3 [25], a dietary analysis software programme developed by the South African Medical Research Council, specific to the nutrient composition of foods in South Africa. The estimated average requirements (EARs) and tolerable upper levels (TULs) for available nutrients from the Institute of Medicine Dietary Reference Intakes were used to evaluate the nutritional adequacy of reported maternal diets [26]. These reference intakes have been used previously to evaluate diet composition in various South African cohorts [27]. A dietary diversity score (DDS) was calculated as an additional measure of diet quality using nine food groups (1. Cereals, roots and tubers, 2. Vegetables and fruits rich in Vitamin A, 3 Other fruit, 4. Other vegetables, 5. Legumes, 6. Meat, poultry and fish, 7. Dairy, 8. Eggs, and 9. Fats and oils) as previously validated and described in South African cohorts $[28,29]$. Each food group was only counted once. 


\section{Infant feeding patterns}

At follow up, mothers reported whether they were, or had ever, exclusively breastfed their infants. If the infants were currently receiving formula, the mothers provided the age when formula had been introduced. Feeding practices were only available until 8 weeks of age for the youngest infant at follow up, so this was chosen at the cut off for Figure 1 to plot feeding patterns for the whole cohort.

\section{Data analysis}

Data were analysed using JMP 14.0. Data were tested for normality and univariate analysis (ANOVA, Kruskal-Wallis/Wilcoxon test for non-parametric data, or Welch's test for normal data with unequal variance) was used to compare maternal dietary intake nutrient levels for mothers living with and without HIV. Differences in the probability that mother's living with compared to without HIV reporting that they experienced food insecurity or had a DDS $<4$ were assessed using Fisher's exact test (2-tail).

To explore overall household food security and diet quality in this cohort, and possible relationships between household food insecurity and infant growth, we conducted comparisons of: 1 . Anthropometry of infants at birth and 12 weeks of age, 2. Apgar scores (one and five minutes), and 3. GMCD milestones attained in infants aged 12 weeks for infants whose mothers reported on food security using adjusted multiple regression models, and Fisher's exact test (2-tail) was used to quantify differences for probability of: 1 . Stunting at birth or 12 weeks of age, 2 . Exclusively breastfeeding at follow up, and 3. Attaining all age-appropriate GMCD milestones, between infants whose mothers reported food insecure conditions compared to those who did not. We also explored whether relationships between suboptimal nutritional environments and infant development would occur to a greater degree in HEU than HUU infants. Using Fisher's exact test (2-tail), we compared probability of: 1 . Stunting at birth or 12 weeks of age, 2 . Exclusively breastfeeding at follow up, and 3. Attaining all age-appropriate GMCD milestones for HEU and HUU infant groups.

Maternal data on food security and dietary recall were only available for mothers whose infants attended follow up, when the questionnaires were administered. Therefore, relationships between maternal HIV status, diet, and reports of food (in)security with infant anthropometric and GMCD outcomes at birth and in infants aged 12 weeks were only examined in this subset (HIV infected: $n=21$, HIV uninfected: $n=10$ ) of the original cohort recruited at birth (HIV infected: $n=$ 32, HIV uninfected: $\mathrm{n}=22$ ).

Variables that are known or suspected confounders for our outcome measures were included as covariables in regression models where the exposure of interest was maternal reports of food (in)security, and variables with $\alpha=0.20$ were retained through stepwise backward elimination for the final models. Maternal covariables included HIV status, age, education, weight at delivery, gravidity, parity, smoke exposure, breastfeeding practices. Infant included anthropometry, gestational age, sex, age (days) at follow up, weight gain from birth to 12 weeks of age. Variables included in final adjusted models for outcomes at birth and 12 weeks of age can be seen in Supplementary tables S1 and S2. With the pilot study's small sample size in consideration, we calculated adjusted retrospective power (AdjP) to determine the probability that the any effects of HEU on infant outcomes found during analyses were true with $80 \%$ certainty $(\mathrm{Adj} P>0.80)$. Findings are presented as unadjusted medians [IQR], with AdjP and $\mathrm{p}$ value from ANCOVA.

\section{Results}

\section{Cohort characteristics}

There were no differences among the 31 (HIV infected $n=21$, HIV uninfected $n=10$ ) mother-infant dyads at follow up for maternal weight at delivery, age, level of education, or reports of food insecurity (Supplementary Table S3). No mothers reported consuming alcohol during pregnancy, and all mothers were non-cigarette smokers, however, one woman reported consuming snuff. Of the infants in attendance at follow up, three were born preterm ( $<37$ weeks), including one HUU infant born at 36 weeks, and two HEU infants, born at 35 and 36 weeks (Supplementary Table S3). There were no differences between HUU and HEU infants for infant sex, gestational age or age at follow up at follow up (Supplementary Table S3).

\section{Food security and nutrients intakes among mothers living with and without HIV}

There were no differences between mothers living with and without HIV for probability of reporting household food insecurity (Table 1). Mothers living with HIV had higher intakes of Vitamin D $(64.5$ [42.0, 84.6] vs. $8.60[0.38,20.8], \operatorname{Adj} \mathrm{P}=0.95, \mathrm{p}=0.002)$ and $\mathrm{Se}(51.7[42.1,73.7]$ vs. 12.6 [7.41, 34.4], AdjP $=0.77, \mathrm{p}<.001)$ compared to mothers living without HIV (Table 1). There were no relationships between maternal HIV status and DDS (Table 1). Full data on absolute nutrient intake levels for mothers living with and without HIV from the 24-hour dietary recall are presented Supplementary table 3.

\section{Relationships between household food insecurity and diet quality}

Mothers who worried about or experienced food runout consumed less animal protein compared to those who did not $(16.3[3.85,30.0]$ vs. 29.0 [19.3, 39.0], $\operatorname{Adj} \mathrm{P}=0.49, \mathrm{p}=0.03$ [Table 2]; 15.4 [3.30, 21.4] vs. 29.0 $[19.7,38.0]$, Adj $\mathrm{P}=0.68, \mathrm{p}=0.01$ [Supplementary table S6]). Mothers who experienced food runout consumed less saturated fatty acids (FA)than mothers who did not $(6.80[5.69,12.9]$ vs. 9.68 [8.88, 14.7], $\mathrm{Adj} \mathrm{P}=0.07$, $\mathrm{p}=0.03$ [Supplementary table S6]). Mothers who worried about food runout consumed lower levels of added sugars $(8.00[0.50,18.8]$ vs. 25.6 $[12.0,41.0], \mathrm{Adj} \mathrm{P}=0.11, \mathrm{p}=0.01$ [Table 2] $)$ and glucose $(1.80[0.00,3.55]$ vs. $3.95[2.40,5.00], \operatorname{Adj} \mathrm{P}=0.19, \mathrm{p}=0.04$ [Table 2]) compared to those who did not, and mothers who experienced food runout (Supplementary table S6) consumed less fructose $(0.40$ [0.00, 6.10] vs. $6.50[1.20,8.15]$, $\operatorname{Adj} \mathrm{P}=0.16, \mathrm{p}=0.01)$, sucrose $(8.40[1.00,17.9]$ vs. $19.1[12.4,30.1]$, $\operatorname{AdjP}=0.05, \mathrm{p}=0.03)$, glucose $(1.20[0.00,3.40]$ vs. $3.95[2.75,5.60]$, $\operatorname{Adj} \mathrm{P}=0.39, \mathrm{p}=0.01)$, added sugars $(8.00[0.30,21.0]$ vs. $17.6[12.0,40.5]$, $\operatorname{Adj} \mathrm{P}=0.05, \mathrm{p}=0.04)$ total sugars $(13.1[7.00,30.9]$ vs. $31.2[24.3,42.5]$, $\operatorname{Adj} \mathrm{P}=0.07, \mathrm{p}=0.02)$ and dietary insoluble fibre $(1.20[0.00,3.20]$ vs. 3.15 $[1.68,4.08], \operatorname{Adj} \mathrm{P}=0.18, \mathrm{p}=0.04)$. Overall, very few mothers had intake of vitamins or minerals that was too high, however, TULs were exceeded for magnesium and sodium (Table 2). There were no relationships between reports of household food insecurity and DDS (Table 2, Supplementary table S6).

Overall, a large proportion of mothers were at risk of inadequate intake of macronutrients, vitamins and minerals (Figure 2). Food insecurity was associated with an increased risk of inadequate intake (median \%EAR met) of vitamin B12 amongst mothers who reported experiencing (66.7 $[12.5,91.7]$ vs. $89.6[67.7,144], \operatorname{Adj} \mathrm{P}=0.20, \mathrm{p}=0.01$ [Supplementary figure S1]) food runout, or an inability to afford balanced meals (66.7 $[19.8,96.9]$ vs. $108[70.8,150], \operatorname{Adj} \mathrm{P}=0.05, \mathrm{p}=0.04$ [Supplementary figure S2]) compared to mothers who did not. Of the mothers who reported worrying about or experiencing food runout, or inability to afford balanced meals, $76.5 \%, 86.7 \%$, and $81.8 \%$ were at risk for inadequate intake, respectively.

\section{Influence of food insecurity on infant Apgar scores and growth outcomes at birth}

Maternal reports of food insecurity did not influence infant gestational age at birth (Supplementary Table S4). However, infants who were from households where mothers reported worrying about food runout (compared to those who had not worried) had higher BBR at birth (10.4 $[9.70,12.0]$ vs. $9.65[8.90,10.3], \operatorname{Adj} P=0.40, p=0.04$, Figure $3 \mathrm{~A})$. Maternal reports of food insecurity (worry about or experience food runout, or inability to afford balanced meals compared to those who did not experience these circumstances) were not associated with any other infant anthropometry at birth (Supplementary Table S4). 
medRxiv preprint doi: https://doi.org/10.1101/19003871; this version posted September 14, 2019. The copyright holder for this preprint (which was not certified by peer review) is the author/funder, who has granted medRxiv a license to display the preprint in perpetuity.

All rights reserved. No reuse allowed without permission.

Table 1. Maternal reports of household food security and nutrient intakes from one 24-hour dietary recall for mothers with and without HIV who attended follow up.

\begin{tabular}{|c|c|c|c|c|}
\hline & $\begin{array}{l}\text { Total } \\
\mathrm{N}=31\end{array}$ & $\begin{array}{l}\text { HIV-uninfected } \\
\qquad(\mathrm{n}=10)\end{array}$ & $\begin{array}{l}\text { HIV-infected } \\
\qquad(\mathrm{n}=21)\end{array}$ & p value \\
\hline \multicolumn{5}{|l|}{ Household food security circumstances (n) } \\
\hline \multicolumn{4}{|l|}{$\begin{array}{l}\text { Maternal reports of worrying about food } \\
\text { runout }\end{array}$} & \multirow[t]{2}{*}{ NS } \\
\hline Never occurs & 14 & 3 & 11 & \\
\hline Occurs often/sometimes & 17 & 7 & 10 & \multirow{3}{*}{ NS } \\
\hline \multicolumn{4}{|l|}{$\begin{array}{l}\text { Maternal reports of experiencing about } \\
\text { food runout }\end{array}$} & \\
\hline Never occurs & 16 & 4 & 12 & \\
\hline Occurs often/sometimes & 15 & 6 & 9 & \multirow{4}{*}{ NS } \\
\hline \multicolumn{4}{|l|}{$\begin{array}{l}\text { Maternal reports of being unable to afford } \\
\text { balanced meals }\end{array}$} & \\
\hline Never occurs & 9 & 2 & 7 & \\
\hline Occurs often/sometimes & 26 & 8 & 14 & \\
\hline \multicolumn{5}{|l|}{ Maternal nutrient intakes } \\
\hline Dietary diversity score (/9) & $4.00(4.00,6.00)$ & $4.00(3.00,5.25)$ & $4.00(3.00,6.00)$ & NS \\
\hline Dietary diversity score $<4$ (n) & 7 & 3 & 4 & NS \\
\hline \multicolumn{5}{|l|}{ Median intake (\%) of TULs by mothers } \\
\hline \multicolumn{5}{|l|}{ Minerals } \\
\hline $\mathrm{Ca}$ & $5.48(3.40,9.56)$ & $7.78(4.09,14.4)$ & $5.28(3.40,7.48)$ & NS \\
\hline $\mathrm{Fe}$ & $24.7(16.7,27.8)$ & $25.0(15.5,30.1)$ & $24.2(16.4,27.8)$ & NS \\
\hline $\mathrm{Mg}$ & $52.9(34.6,81.1)$ & $80.0(33.0,99.1)$ & $48.0(38.4,64.0)$ & NS \\
\hline $\mathrm{P}$ & $14.9(10.8,19.3)$ & $18.1(10.4,21.4)$ & $14.3(10.5,18.3)$ & NS \\
\hline $\mathrm{Na}$ & $69.9(48.2,154)$ & $92.4(43.9,171)$ & $69.9(47.8,146)$ & NS \\
\hline $\mathrm{Zn}$ & $20.9(16.8,29.3)$ & $17.4(15.2,23.8)$ & $23.7(19.8,29.9)$ & NS \\
\hline $\mathrm{Cu}$ & $7.70(5.50,11.0)$ & $11.4(4.97,13.4)$ & $7.40(5.20,9.55)$ & NS \\
\hline Se & $7.00(4.15,9.78)$ & $1.86(1.09,5.08)$ & $7.63(6.21,10.9)$ & $<.001$ \\
\hline $\mathrm{Mn}$ & $12.7(7.52,17.6)$ & $15.7(6.64,21.9)$ & $10.2(7.28,16.2)$ & NS \\
\hline I & $8.36(4.09,16.0)$ & $8.27(2.30,16.1)$ & $8.36(5.86,17.2)$ & NS \\
\hline \multicolumn{5}{|l|}{ Vitamins } \\
\hline Vitamin A & $14.1(10.2,23.8)$ & $14.1(11.1,24.2)$ & $14.3(10.0,23.5)$ & NS \\
\hline Niacin & $44.0(30.6,55.7)$ & $41.6(29.1,57.9)$ & $46.6(28.5,55.9)$ & NS \\
\hline Vitamin B6 & $2.88(1.60,3.80)$ & $2.61(1.37,5.19)$ & $3.13(1.72,3.72)$ & NS \\
\hline Folate & $25.9(20.5,31.9)$ & $23.9(18.3,38.3)$ & $27.8(20.7,31.2)$ & NS \\
\hline Vitamin C & $1.15(0.40,3.65)$ & $1.58(0.11,4.74)$ & $1.10(0.53,3.13)$ & NS \\
\hline Vitamin D & $4.29(0.83,7.86)$ & $0.86(0.04,2.08)$ & $6.45(4.20,8.46)$ & 0.002 \\
\hline Vitamin E & $0.68(0.44,1.19)$ & $0.52(0.33,1.17)$ & $0.80(0.47,1.33)$ & NS \\
\hline \multicolumn{5}{|l|}{ Median intake (\%) of EARs by mothers } \\
\hline \multicolumn{5}{|l|}{ Macronutrients } \\
\hline Protein & $66.6(49.9,90.4)$ & $68.7(60.6,87.7)$ & $65.5(48.9,99.5)$ & NS \\
\hline Carbohydrates & $98.7(63.6,113)$ & $81.8(56.7,81.8)$ & $99.8(77.7,118)$ & NS \\
\hline
\end{tabular}




\begin{tabular}{|l|c|c|c|c|}
\hline Vitamin A & $47.0(34.175 .4)$ & $46.9(36.8,77.6)$ & $47.8(33.4,78.3)$ & NS \\
\hline Thiamin & $90.0(56.7,111)$ & $88.3(53.5,116)$ & $90.0(57.5,118)$ & NS \\
\hline Riboflavin & $55.4(43.1,74.6)$ & $38.9(24.4,96.9)$ & $58.5(49.6,74.2)$ & NS \\
\hline Niacin & $119(72.3,150)$ & $112(69.4,156)$ & $125(75.4,150)$ & NS \\
\hline Vitamin B6 & $170(88.7,223)$ & $139(80.6,306)$ & $184(97.4,219)$ & NS \\
\hline Folate & $54.2(43.1,70.9)$ & $47.1(39.9,85.1)$ & $61.8(45.9,69.2)$ & NS \\
\hline Vitamin B12 & $70.8(62.5,108)$ & $68.8(9.38,102)$ & $75.0(66.7,133)$ & NS \\
\hline Vitamin C & $23.0(8.00,73.0)$ & $31.5(2.25,92.7)$ & $22.0(10.5,62.5)$ & NS \\
\hline Vitamin D & $42.9(8.30,78.6)$ & $8.60(0.38,20.8)$ & $64.5(42.0,84.6)$ & 0.002 \\
\hline Vitamin E & $42.5(27.4,74.3)$ & $32.7(20.8,73.1)$ & $49.4(29.5,82.8)$ & NS \\
\hline Minerals & & & & \\
\hline Ca & $17.1(10.6,29.9)$ & $24.3(12.7,44.5)$ & $16.5(10.6,23.4)$ & NS \\
\hline Fe & $171(115,192)$ & $168(112,192)$ & $173(106,208)$ & NS \\
\hline Mg & $71.3(45.7,111)$ & $110(44.0,136)$ & $63.4(50.8,87.1)$ & NS \\
\hline P & $103(68.3,133)$ & $125(41.2,147)$ & $98.8(69.5,126)$ & NS \\
\hline Zn & $78.9(64.5,113)$ & $66.8(47.4,91.6)$ & $91.0(73.3,115)$ & NS \\
\hline Cu & $77.0(52.8,110)$ & $112(48.1,127)$ & $74.0(50.4,95.5)$ & NS \\
\hline Se & $47.5(28.1,66.3)$ & $12.6(7.41,34.4)$ & $51.7(42.1,73.7)$ & $<.001$ \\
\hline I & $44.0(21.5,80.9)$ & $43.5(12.1,80.4)$ & $44.0(30.4,90.4)$ & NS \\
\hline
\end{tabular}

Data from mother-infant dyads that attended follow up are presented as median (IQR) and $p$ values are from univariate analysis (Kruskal-Wallis/Wilcoxon test for non-parametric data; ANOVA for normal data with equal variance). Dietary diversity score was calculated using nine food groups, only counting each food groups once (refs). Percent intake of TULs and EARs were calculated using the Institute of Medicine's TULs for minerals and vitamins for lactating women 14-18, 1930 or 31-50 years of age [26]. Iodised salt was assumed to be consumed by all mothers, as the majority of salt consumed in South Africa is iodised [64]. TULs = Tolerable upper levels; EARs = Estimated average requirements.

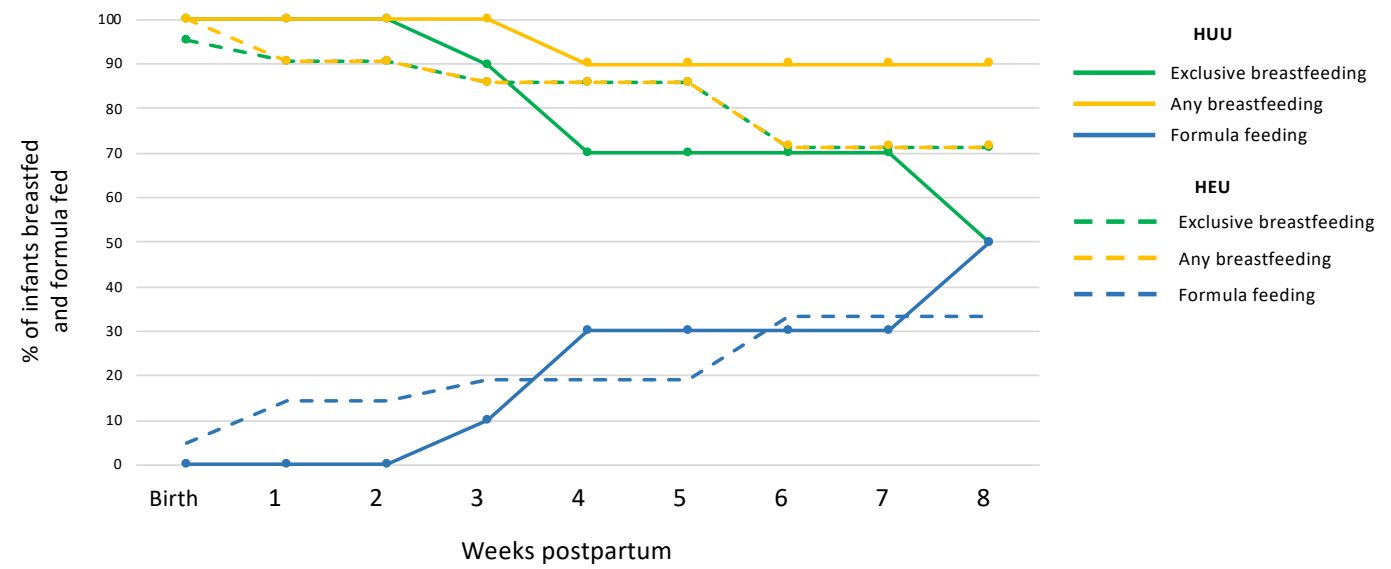

Figure 1. Feeding patterns from birth to 8 weeks postpartum in HUU and HEU infants. There were no differences in the likelihood of being exclusively breastfed (EBF) at 12 weeks of age for HUU $(n=10)$ compared to HEU $(n=21)$ infants $([p>0.05]$, Fisher's exact 2-Tail). Data on feeding practices were available for the whole cohort from birth to 8 weeks postpartum. Each point on the line represents the proportion (\%) of HUU or HEU exclusively breastfed, receiving any breastmilk, or were formula fed at that time (weeks). HUU = HIV-unexposed, uninfected infant; HEU = HIV-exposed, uninfected infant. 
Table 2. Maternal nutrient intake from one 24-hour dietary recall for mothers who report experiencing food insecure compared to those who do not experience food insecurity.

\begin{tabular}{|c|c|c|c|}
\hline & \multicolumn{3}{|c|}{ Do you worry about food runout? } \\
\hline & NO & YES & \multirow{2}{*}{$p$ value } \\
\hline & $\mathrm{n}=14$ & $\mathrm{n}=17$ & \\
\hline Dietary diversity score (/9) & $4.50(4.00,6.00)$ & $4.00(3.00,5.50)$ & NS \\
\hline Dietary diversity score <4 (n) & 2 & 5 & NS \\
\hline \multicolumn{4}{|l|}{ Absolute intakes } \\
\hline \multicolumn{4}{|l|}{ Macronutrients } \\
\hline Moisture (g) & $868(629,1029)$ & $670(507,1092)$ & NS \\
\hline Energy $(\mathrm{kJ})$ & $5601(4792,6855)$ & $5204(3264,8103)$ & NS \\
\hline Nitrogen $(g)$ & $7.15(5.55,8.82)$ & $4.63(3.93,6.57)$ & NS \\
\hline Total protein $(\mathrm{g})$ & $51.4(43.8,63.2)$ & $37.9(26.3,53.8)$ & NS \\
\hline Plant protein $(\mathrm{g})$ & $19.6(17.1,26.0)$ & $22.3(11.1,37.5)$ & NS \\
\hline Animal protein $(\mathrm{g})$ & $29.0(19.3,39.0)$ & $16.3(3.85,30.0)$ & 0.03 \\
\hline Total fat $(\mathrm{g})$ & $36.5(30.0,51.8)$ & $25.8(20.6,65.1)$ & NS \\
\hline Carbohydrates, avail. (g) & $162(159,200)$ & $161(97.0,277)$ & NS \\
\hline Starch $(g)$ & $5.6(0.18,10.3)$ & $0.00(0.00,8.1)$ & NS \\
\hline Glucose (g) & $3.95(2.40,5.00)$ & $1.80(0.00,3.55)$ & 0.04 \\
\hline Fructose (g) & $6.50(0.90,7.45)$ & $0.70(0.00,6.30)$ & NS \\
\hline Sucrose $(g)$ & $17.7(12.0,32.9)$ & $12.0(1.70,23.6)$ & NS \\
\hline Maltose $(g)^{1}$ & & 0.1 & \\
\hline \multicolumn{4}{|l|}{ Galactose $^{2}$} \\
\hline Lactose $(\mathrm{g})$ & $0.00(0.00,2.10)$ & $0.00(0.00,0.05)$ & NS \\
\hline Total sugars $(\mathrm{g})$ & $30.3(23.4,41.7)$ & $15.8(8.05,34.5)$ & NS \\
\hline Added sugar (g) & $25.6(12.0,41.0)$ & $8.00(0.50,18.8)$ & 0.01 \\
\hline Total dietary fibre $(\mathrm{g})$ & $13.4(11.0,16.7)$ & $12.2(6.70,21.1)$ & NS \\
\hline Insoluble dietary fibre (g) & $2.75(1.33,3.60)$ & $1.40(0.00,3.45)$ & NS \\
\hline Soluble dietary fibre (g) & $1.85(1.05,2.70)$ & $0.80(0.00,3.40)$ & NS \\
\hline Ash $(\mathrm{g})$ & $6.05(4.65,6.53)$ & $9.30(4.30,14.8)$ & NS \\
\hline Non-starch polysaccharides (g) & $4.20(2.13,5.98)$ & $2.10(0.00,6.45)$ & NS \\
\hline Insoluble NSP (g) & $2.25(1.15,3.03)$ & $1.40(0.00,3.05)$ & NS \\
\hline Soluble NSP (g) & $1.85(1.05,2.70)$ & $0.80(0.00,3.40)$ & NS \\
\hline Lignin $(g)$ & $0.20(0.10,0.30)$ & $0.10(0.00,0.30)$ & NS \\
\hline \multicolumn{4}{|l|}{ Amino acids } \\
\hline Isoleucine (g) & $1.78(1.34,2.26)$ & $1.24(0.80,1.83)$ & NS \\
\hline Leucine $(\mathrm{g})$ & $3.48(2.68,4.06)$ & $2.18(1.51,3.34)$ & NS \\
\hline lysine $(\mathrm{g})$ & $2.59(1.84,3.67)$ & $1.52(1.04,2.65)$ & NS \\
\hline Methionine (g) & $0.96(0.88,1.17)$ & $0.65(0.47(0.91)$ & 0.01 \\
\hline Phenylalanine $(\mathrm{g})$ & $2.01(1.53,2.35)$ & $1.32(0.90,2.11)$ & NS \\
\hline Threonine $(\mathrm{g})$ & $1.73(1.33,2.10)$ & $1.08(0.76,1.71)$ & NS \\
\hline Tryptophan (g) & $0.61(0.53,0.71)$ & $0.38(0.30,0.57)$ & 0.02 \\
\hline Valine $(g)$ & $212(1.67,2.45)$ & $1.38(0.98,2.23)$ & NS \\
\hline Arginine (g) & $2.53(1.86,3.36)$ & $1.48(1.18,2.77)$ & NS \\
\hline Histidine (g) & $1.14(0.85,1.37)$ & $0.73(0.44,1.27)$ & 0.05 \\
\hline
\end{tabular}




\begin{tabular}{|c|c|c|c|}
\hline Cystine (g) & $0.62(0.53,0.87)$ & $0.48(0.31,0.66)$ & 0.02 \\
\hline Tyrosine (g) & $1.12(0.87,1.44)$ & $0.79(0.46,1.06)$ & NS \\
\hline Alanine (g) & $1.74(1.28,2.28)$ & $1.16(0.67,1.65)$ & 0.04 \\
\hline Aspartic acid (g) & $3.01(2.24,3.71)$ & $1.87(1.12,2.92)$ & NS \\
\hline Glutamic acid (g) & $6.24(4.72,8.31)$ & $4.43(1.96,5.83)$ & NS \\
\hline Glycine (g) & $1.47(1.03,2.10)$ & $1.02(0.52,1.47)$ & NS \\
\hline Proline (g) & $2.00(1.47,2.63)$ & $1.36(0.56,1.87)$ & 0.05 \\
\hline Serine $(g)$ & $1.65(1.50,2.14)$ & $1.20(0.86,1.67)$ & 0.03 \\
\hline Hydroxyproline (g) & $0.10(0.06,0.22)$ & $0.00(0.00,0.11)$ & NS \\
\hline \multicolumn{4}{|l|}{ Fatty acids and cholesterol } \\
\hline Saturated FA (g) & $9.55(8.56,15.2)$ & $7.88(5.74,11.4)$ & NS \\
\hline Mono-unsaturated FA (g) & $12.5(10.5,15.8)$ & $10.9(7.19,21.8)$ & NS \\
\hline Polyunsaturated FA (g) & $8.70(6.26,15.3)$ & $5.46(3.37,20.2)$ & NS \\
\hline \multicolumn{4}{|l|}{ Single trans FA $(g)^{2}$} \\
\hline \multicolumn{4}{|l|}{ Double trans FA $(\mathrm{g})^{2}$} \\
\hline Total trans FA (g) & $0.20(0.16,0.82)$ & $0.06(0.00,0.35)$ & NS \\
\hline Cholesterol (mg) & $291(236,544)$ & $117(33.0,420)$ & 0.04 \\
\hline \multicolumn{4}{|c|}{ Median intake (\%) of TULs by mothers } \\
\hline \multicolumn{4}{|c|}{ Minerals } \\
\hline Calcium (Ca) & $5.88(4.56,9.55)$ & $4.52(2.76,10.5)$ & NS \\
\hline Iron $(\mathrm{Fe})$ & $25.6(21.7,27.1)$ & $18.2(12.8,31.6)$ & NS \\
\hline Magnesium (Mg) & $52.1(44.6,71.4)$ & $57.1(30.0,97.0)$ & NS \\
\hline Phosphorus (P) & $16.7(12.9,19.9)$ & $12.1(9.14,18.9)$ & NS \\
\hline Sodium (Na) & $67.5(48.0,91.7)$ & $127(42.5,210)$ & NS \\
\hline Zinc (Zn) & $22.3(20.1,29.6)$ & $19.6(14.7,27.1)$ & NS \\
\hline Copper (Cu) & $8.15(6.35,10.6)$ & $6.90(3.95,12.1)$ & NS \\
\hline Selenium (Se) & $7.56(5.41,11.6)$ & $6.18(1.86,9.73)$ & NS \\
\hline Manganese (Mn) & $12.8(8.46,18.2)$ & $12.7(5.59,18.9)$ & NS \\
\hline Iodine (I) & $7.82(3.73,12.8)$ & $13.6(4.59,19.1)$ & NS \\
\hline \multicolumn{4}{|l|}{ Vitamins } \\
\hline Vitamin A & $14.2(11.2,18.8)$ & $14.1(8.57,26.9)$ & NS \\
\hline Niacin & $47.4(42.0,55.6)$ & $40.0(24.4,60.6)$ & NS \\
\hline Vitamin B6 & $3.20(2.74,3.68)$ & $2.14(1.22,4.17)$ & NS \\
\hline Folate & $27.8(21.3,29.6)$ & $24.1(19.8,48.6)$ & NS \\
\hline Vitamin C & $1.28(0.90,2.45)$ & $0.60(0.08,6.38)$ & NS \\
\hline Vitamin D & $4.73(4.15,8.76)$ & $1.39(0.39,7.86)$ & NS \\
\hline Vitamin E & $0.73(0.49,1.21)$ & $0.68(0.41,1.30)$ & NS \\
\hline
\end{tabular}

Data from mother-infant dyads that attended follow up are presented as mean \pm SD or median (IQR) and $p$ values are from univariate analysis (Kruskal-Wallis/Wilcoxon test for non-parametric data; ANOVA for normal data with equal variance). Dietary diversity score was calculated using nine food groups, only counting each food groups once (refs). Percent intake of TULs were calculated using the Institute of Medicine's TULs for minerals and vitamins for lactating women 14-18, 19-30 or 31-50 years of age [26]. Iodised salt was assumed to be consumed by all mothers, as the majority of salt consumed in South Africa is iodised [64].TULs = Tolerable upper levels. ${ }^{1}$ Only one mother consumed maltose. ${ }^{2}$ None consumed by mothers. 


\section{Percent estimated average requirements (EARs) met}
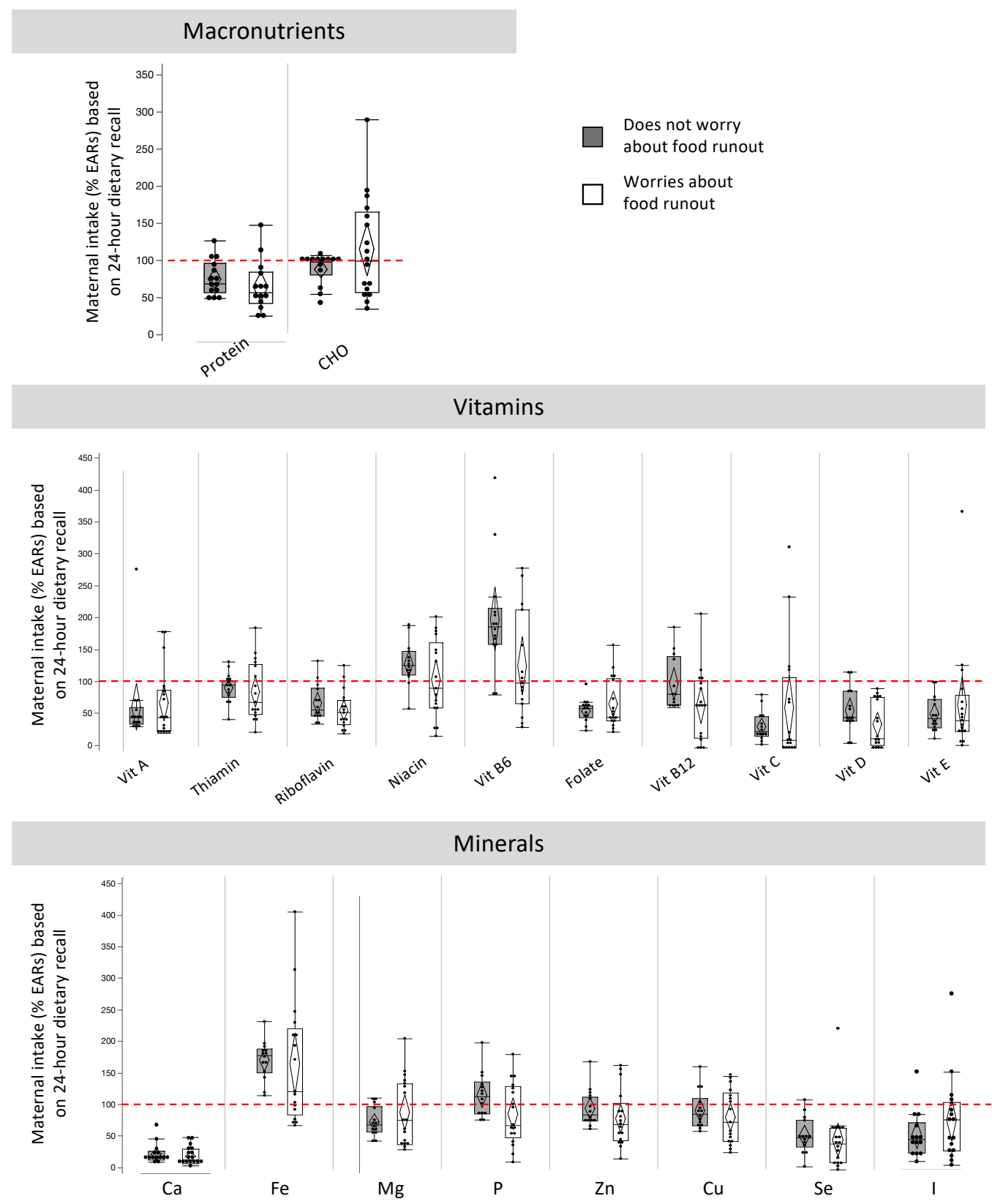

Figure 2. Maternal intake of estimated average requirements for macronutrients, vitamins and minerals for mothers who report worrying about food runout (compared to not worrying). Maternal reports of food insecurity did not associate with intake levels of macronutrients, vitamins or minerals. Many women, irrespective of food security reports, are at risk of inadequate macronutrient, vitamin and mineral intakes. Percent intake of EARs for nutrients were calculated for lactating women $14-18,19-30$ or 31-50 years of age [26]. No EARs are available for total fat. Calculations for EAR for total protein considered maternal weight at time of dietary recall. Data are \% intake of EAR reported in maternal dietary recall for macronutrients (quartiles, median lines and $95 \%$ confidence diamonds, ${ }^{*} p<0.05$ [ANOVA for normal distribution/equal variance; Kruskal-Wallis/Wilcoxon test for non-parametric data; or Welch's test for normal data/unequal variance]). $\mathrm{CHO}=$ carbohydrates. 
Food insecurity and infant outcomes at birth and 12 weeks PP

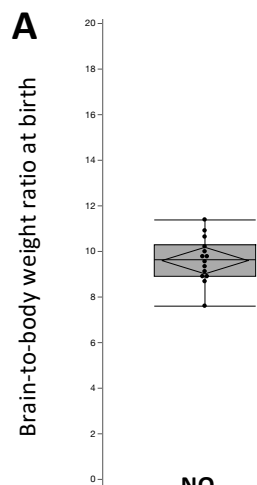

NO

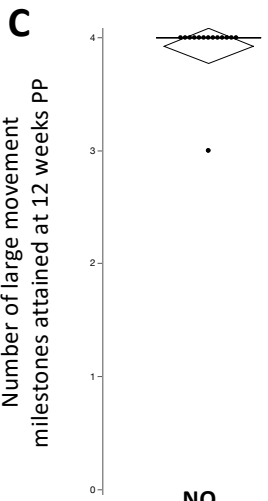

NO

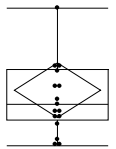

YES

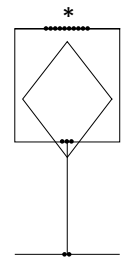

YES

Food insecurity and risk of stunting at birth and 12 weeks PP

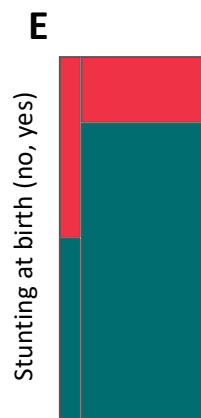

HUU, HEU
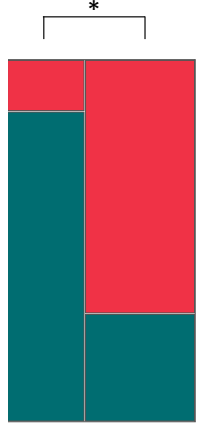

HUU, HEU YES

Do you worry about food runout?

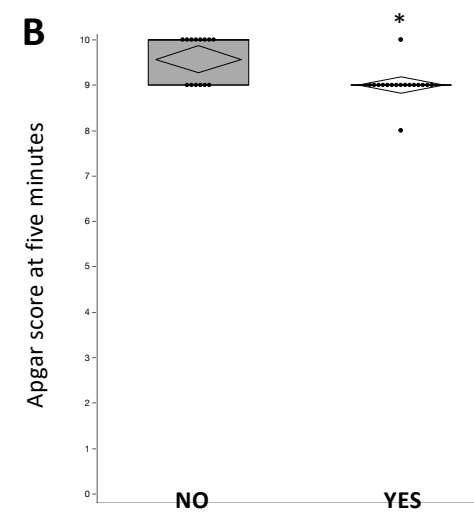

D
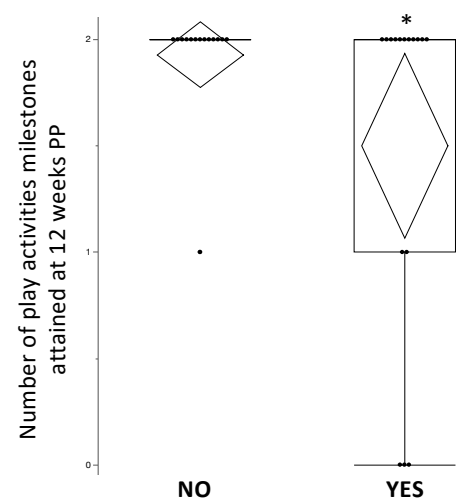

$\mathbf{F}$

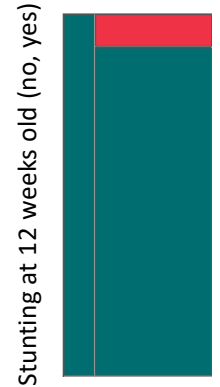

HUU, HEU

NO

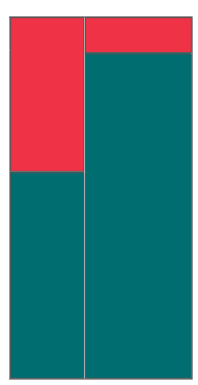

HUU, HEU

YES
Does not worry

about food runout

Worries about

food runout

Do you worry about food runout?

Figure 3. Maternal reports of worrying about food runout affect infant growth and neurodevelopment at birth and 12 weeks of age, and cooccurrence of maternal HIV and food insecurity increases risk of stunting at birth. Maternal reports of worrying about food insecurity (compared to not worrying) associate with higher brain-to-body weight ratio at birth ( $A$; $A d j P=0.40, p=0.04$ ), lower Apgar score at five minutes postpartum ( $B$; $A d j P=0.55, p=0.001)$, and attainment of fewer large movement $(C ; A d j P=0.44, p=0.03)$ and play activity $(D ; A d j P=0.58, p=0.02)$ milestones. Amongst infants whose mothers report worrying about food runout, risk of stunting at birth is greater for HEU compared to HUU infants ( $E$; $p=0.04$, Fisher's exact test). The red line represents the proportion of infants who had stunting at birth or 12 weeks PP. Outlier box plots are measured anthropometry, Apgar scores and number of GMCD milestones attained (quartiles, median lines and 95\% confidence diamonds, ${ }^{*} p<0.05$ [ANCOVA]). Mosaic plots are proportion $(\%)$ of HUU or HEU infants who have stunting (<-2 SD length-for-age standardised according to WHO child growth standards [21]) at birth and 12 weeks old. GMCD = Guide for monitoring child development. HUU = HIV-unexposed, uninfected infant; HEU = HIV-exposed, uninfected infant. 
Apgar scores at one minute were not impacted by maternal reports of food security; however, Apgar scores at five minutes were slightly, but not notably, lower for infants whose mothers reported sometimes or often worrying about food runout (compared to those who never worried; 9.00 $[9.00,9.00]$ vs. $10.0[9.00,10.0], \operatorname{Adj} \mathrm{P}=0.55, \mathrm{p}=0.02$ [Figure 3B]). There were no differences in infant Apgar scores at one and five minutes, or trajectory of scores between one and five minutes, for HUU and HEU infants whose mothers reported food insecurity compared those who did not (Supplementary Figure 4).

\section{Influence of food insecurity on growth outcomes in 12 week old infants}

There were no differences for infant head circumference, weight, BMI, or length in infants aged 12 weeks, or weight gain from birth to 12 weeks postpartum in relation to measures of food security (Supplementary Table S4).

\section{HEU may increase vulnerability to effects of food insecurity on risk of stunting at birth}

Among infants whose mothers reported worrying about food runout, HEU infants had increased risk of stunting at birth compared to HUU infants ( $p=0.04$, Fisher's exact test [2-tail] [Figure 3E]). Maternal HIV status did not influence the relationship between maternal reports of food insecurity and any other infant outcomes at birth or 12 weeks postpartum.

\section{Influence of food insecurity on neurodevelopmental outcomes in 12 week old infants}

All but one infant, who was HUU, received a GMCD assessment at their follow up appointment. Maternal reports of worrying about food runout (compared to not worrying) associated with attainment of fewer large movement $(4.00[3.00,4.00]$ vs. 4.00 [4.00, 4.00], $\mathrm{Adj} \mathrm{P}=0.44, \mathrm{p}=0.03$ [Supplementary Table S4]) and play activities milestones (2.00 [1.00, 2.00] vs. $2.00[2.00,2.00$ ], $\operatorname{Adj} \mathrm{P}=0.58, \mathrm{p}=0.02$ [Supplementary Table $\mathrm{S} 4])$. The number of expressive or receptive language, fine movement, or relating and response behaviour milestones attained in infants aged 12 weeks was not affected by maternal reports of food insecurity (Supplementary Table S4).

The probability of attaining all 1-3 month GMCD expressive and receptive language, large movement, play activities and relating and response behaviour milestones did not associate with maternal reports of household food insecurity (Supplementary figure S5A, C, E). No comparisons were made for fine movement outcomes between infants exposed to food insecure conditions compare to those who were not, as all infants who were 1-3 months of age at follow up met all ageappropriate fine movement milestones. At 3-5 months, there were no differences in the proportion of infants who attained fine movement and relating and response behaviour milestones based on maternal reports of food security (Supplementary figure S5B, D, F). No comparisons were made for expressive and receptive language, large movement, or play activities, as all infants 3-5 months of age at follow up had met these milestones. It was not possible to further stratify these comparisons based on maternal HIV status due to our small sample size.

\section{Discussion}

As infectious disease and malnutrition often coexist, it is critical to understand how food insecure circumstances and maternal malnutrition influence the developmental trajectories of the increasing number of children born each year who are HIV-exposed, but uninfected. Amongst children infected with HIV, the cooccurrence of malnutrition is known to exacerbate the disease's adverse effects, and associates with poorer prognosis [30]. HIV-infection has a definite impact on growth and neurodevelopmental outcomes of children [6-9], and malnutrition, which alone positions children to be more vulnerable to more frequent and severe infections [31], may have an additive negative effect on growth and health trajectories [32].

In this small pilot feasibility study, exploratory analyses found that HEU infants exposed to household food insecurity had increased risk of stunting at birth compared to HUU infants whose mothers also reported food insecure conditions, suggesting that HEU infants may be more vulnerable to the programming effects of suboptimal nutrition in utero and postnatally than their HUU counterparts. Stunting is the most common manifestation of infant undernutrition globally [33], increasing morbidity and mortality in children in early life, and increasing one's risk of metabolic disease while reducing neurodevelopmental and economic capacity later in life [34]. Stunting is common amongst children living with HIV who are under 5 years and improves overtime with ART treatment [35], however, the extent to which HEU children are persistently at risk for stunting is not well understood. In our cohort, there were 11 infants who were stunted at birth, and five who were stunted at 12 weeks postpartum. When examining stunting by HIV exposure groups, we observed that amongst infants whose mothers worried about food runout, HEU infants were at an increased risk of stunting compared to HUU infants at birth, but not at follow up. This finding suggests that the effects of in utero HIV exposure and food insecurity on infant length at birth may not persist at 12 weeks postpartum, and infants with low length-for-age at birth may catch up in growth in the first few months of age. Of note, the number of HUU infants 12 weeks of age in our cohort was small, and as such, comparisons between groups should be interpreted with caution. Our findings should be replicated in larger cohorts to determine whether HEU infants exposed to food insecure conditions are indeed more vulnerable to stunting than their HUU counterparts, and whether or not these infants may exhibit catch up growth, an effect known to associate with poor metabolic and cardiovascular outcomes later in life [36].

Suboptimal maternal nutrition during the prenatal period is also known to associate with asymmetric IUGR and brain sparing [23], resulting in a higher BBR at birth and increasing a child's risk of motor hyperactivity, and poorer language, cognitive, and motor outcomes at 10 years of age [37], stunted immune functioning [38,39] and increased risk of metabolic disease later in life [40]. We found higher BBR at birth amongst infants whose mothers reported food insecure conditions, consistent with reports of associations between maternal malnutrition and brain sparing [23] Maternal HIV infection is also implicated as a risk factor for IUGR [41], however, risk of asymmetric IUGR and brain sparing for infants exposed to HIV in utero is not well characterised, and we found no differences in BBR between HUU and HEU infants exposed to food insecure conditions versus not. This suggests that HEU infants in this cohort were not at an increased risk of brain sparing. To our knowledge, this is the first study to use a measure of BBR to look at differential risk of brain sparing among HUU and HEU infants exposed to suboptimal maternal nutrition in utero and postnatally, and larger cohort studies with higher power should further investigate these relationships.

The detrimental impacts of maternal malnutrition on infant neurodevelopment are well established [42], and whilst children perinatally infected with HIV have lower Apgar scores [43], and show poorer motor, cognitive and behavioural development compared to uninfected counterparts as early as 3 months of age [6-9], the neurodevelopmental trajectories of HEU children are poorly understood in part because studies often vary greatly in design, measurement tools, 
cohort demographics, and findings [13,14,44-47]. Here, we observed slightly lower Apgar scores at five minutes amongst infants whose mothers reported worrying about or experiencing food runout, irrespective whether or not the infant was HUU or HEU. Importantly, these differences were small with low power, and their clinical relevance is unlikely. We also found associations between maternal reports of food insecurity and attainment of play activities and large movement milestones in infants aged 12 weeks, irrespective of maternal HIV status. Further, both HUU and HEU infants 1-3 months of age whose mothers reported food insecure conditions did not meet GMCD 1-3 months milestones for receptive language, large movement, relating and response behaviour or play activities. This is in contrast to HUU and HEU infants aged 3-5 months who met all 3-5 month GMCD neurodevelopmental milestones (except for fine movement), irrespective of household food security status. In disagreement with our hypothesis, these findings suggest that the effects of household food insecurity, possibly resulting in maternal malnutrition, on neurodevelopment were not exacerbated by exposure to HIV in the womb. These data also suggest that whilst food insecure circumstances influence neurodevelopmental milestone attainment in infants who are 1-3 months of age, effects of food insecurity on GMCD milestones may not persist beyond 2 months. As the absence of effect at 3-5 months may be owing to our small sample size and low power, further study in a larger cohort and more longitudinal data are required to determine how infant development may change overtime in response to household food insecurity.

Maternal nutrient intakes during pregnancy and the postpartum period are critical to supporting rapid growth and development of the infant [1], and maternal diet in part determines the nutritional composition of breastmilk [48]. Differences in maternal nutrient intakes between mothers living with and without HIV were minimal, and mothers were at risk for inadequate macronutrient intakes irrespective of food insecurity reports, and mothers experiencing food insecurity consumed less animal protein, sugars and insoluble fibre, and more saturated FA. We also found maternal reports of experiencing food insecurity associated with lower vitamin B12, and a large proportion of mothers, irrespective of food insecurity circumstances, were at risk for inadequate intakes. Inadequate maternal vitamin B12 intakes have shown to cause secondary deficiencies in breastfed infants in the first six months of life, leading to delayed growth and neurodevelopment [49]. Iron intake was not influenced by food insecurity, and it is promising that most mothers exceeded EARs, but not TULs, for iron, which may be the result of public health efforts to prevent and treat anaemia in pregnant women in South Africa. Early detection of maternal nutrient deficiencies allows early intervention and potential mitigation of adverse pregnancy outcomes and long-term developmental impacts for infants who are breastfed, and these preliminary results suggest that food insecurity may influence maternal nutrient status. Importantly, our single dietary recall prevented us from determining whether these deficiencies may have persisted long term or are small fluctuations, limiting our ability to infer the degree they may have secondary consequences for the mother and developing infant.

As ART coverage and viral suppression for pregnant women living with HIV has increased, recommendations around postnatal feeding practices have evolved to promote breastfeeding for women living with HIV exclusively for the first 6 months postpartum [50], with continuation of breastfeeding through mixed feeds thereafter until 24 months postpartum [51]. Breastfeeding benefits include increased child cognitive scores, decreased risk of contraction of common childhood infections, and decreased rates of overweight and diabetes in later life [52]. We observed slightly higher retention of EBF amongst mothers living without HIV compared to those living with HIV. Food insecurity is a known barrier to exclusive breastfeeding [53], and mothers experiencing food insecurity may be more likely to return to work soon after birth [54], or may have challenges maintaining milk supply due to inadequate nutrition [55]. In agreement with this, we found that mothers who never experienced food runout or were always able to afford balanced meals were more likely to be exclusively breastfeeding at follow up. Our short follow up time and small sample size limited our ability to examine the effect of exclusive breastfeeding duration on infant outcomes. Yet, infant growth and neurodevelopment from birth to 12 postpartum did not appear to be influenced by exclusive breastfeeding status at 12 weeks postpartum.

Further, whilst it is known that altered maternal endocrine and metabolic status can restructure the breast milk microbiome and immune and nutrient factors therein [56,57], how maternal HIV infection may alter breastmilk composition is not well understood. Investigation of breastmilk immune factors among women living with HIV remains limited, and among the few studies that have measured these factors, varied results have been reported. Higher levels of non-specific IgA [58] and $\operatorname{IgG}[58,59]$ have been measured in breastmilk from women living with HIV, and higher levels of fucosylated human milk oligosaccharides in breast milk are associated with lower infant mortality among HEU infants, but not HEI, during breastfeeding [60]. There is opportunity to better understand how the benefits of exclusive breastfeeding, including improved maternal health outcomes [61] and constituents in breastmilk [62], could be protective against any adverse effects of exposure to HIV in the womb on child growth and neurodevelopment.

Whilst our study's small sample size and limited longitudinal data restricts the generalisability of our findings and the power of our analyses, we were successful in recruiting women to study the cooccurring effects of food insecurity and in utero HIV exposure on maternal dietary intakes and infant outcomes at two time points, and we are now conducting a larger prospective pregnancy and birth cohort study at Kalafong Hospital where we will further investigate relationships that have emerged in exploratory pilot study analyses. There was loss to follow up in this cohort, which may have resulted in sample bias at follow up. While multiple attempts were made to contact mothers whom missed follow up appointments, this population is highly mobile and study participant retention remains difficult. To our knowledge, this prospective cohort study is amongst the first few investigating relationships between maternal nutrition and food security and infant growth and neurodevelopment among a population of HIV-exposed, uninfected infants in comparison to HIV-unexposed controls.

Overall, our findings suggest that food insecurities, and the likely ensuing poor maternal nutritional status, adversely affect the growth and neurodevelopment of a South African cohort of HUU and HEU infants in the first four months of life, and at least for some measures, the effects of a suboptimal early life nutritional environment may be most detrimental for infants exposed to HIV in the womb. The perinatal window is a key period to target to improve infant developmental outcomes. Whether interventions that focus on maternal/child nutritional status and food security at this time improve outcomes for the 1.5 million HIV-exposed infants born annually, who may be even more vulnerable to the programming effects suboptimal nutrition in utero and postnatally [63], remains to be determined. 


\section{Acknowledgments}

The authors would like to thank the participating families and health care workers in Pretoria, for without whom this research would not be possible, and Dr. Chrisna Durandt, who performed the flow cytometry.

This research is funded by the Collaborative Initiative for Paediatric HIV Education and Research (CIPHER), the Faculty of Science, Carleton University, and the Canadian Institutes of Health Research (CIHR). MW is supported by a Canadian Graduate Scholarship-Master's from CIHR.

\section{Author Contributions}

Conceptulalisation: KLC, TR, UF; Methodology: KLC, MW, TR; Investigation: MW, KLC, ED, TR, UF; Analysed data: MW, ED, KLC; Wrote paper: MW, KLC; Reviewed and revised paper: TR, UF, ED, MW, KLC.

\section{References}

1. Georgieff MK. Nutrition and the developing brain: nutrient priorities and measurement. Am J Clin Nutr. 2007,85(2),614S-620S.

2. Krakowiak P; Walker CK; Bremer AA; Baker AS; Ozonoff S; Hansen $\mathrm{RL}$; et al. Maternal metabolic conditions and risk for autism and other neurodevelopmental disorders. Pediatrics. 2012,129(5),e1121-8.

3. BARKER DJP; THORNBURG KL. The Obstetric Origins of Health for a Lifetime. Clin Obstet Gynecol. 2013,56(3),511-9.

4. Pfeifer C; Bunders MJ. Maternal HIV infection alters the immune balance in the mother and fetus; implications for pregnancy outcome and infant health. Curr Opin Hiv Aids [Internet]. 2016,11(2),138-45.

5. Brocklehurst $P$; French $R$. The association between maternal HIV infection and perinatal outcome: a systematic review of the literature and meta-analysis. Br J Obstet Gynaecol. 1998,105(8),836-48.

6. Boivin MJ; Green SD; Davies AG; Giordani B; Mokili JK; Cutting WA. A preliminary evaluation of the cognitive and motor effects of pediatric HIV infection in Zairian children. Health Psychol. 1995,14(1),13-21.

7. Msellati P; Lepage P; Hitimana DG; Van Goethem C; Van de Perre P; Dabis F. Neurodevelopmental testing of children born to human immunodeficiency virus type 1 seropositive and seronegative mothers: a prospective cohort study in Kigali, Rwanda. Pediatrics. 1993,92(6),843-8.

8. Drotar D; Olness K; Wiznitzer M; Schatschneider C; Marum L; Guay L; et al. Neurodevelopmental outcomes of Ugandan infants with HIV infection: An application of growth curve analysis. Heal Psychol. 1999,18(2),114-21.

9. Knight WG; Mellins CA; Levenson RL; Arpadi SM; Kairam R. Brief report: effects of pediatric HIV infection on mental and psychomotor development. J Pediatr Psychol. 2000,25(8),583-7.

10. Volmink J; Siegfried NL; Merwe L van der; Brocklehurst $P$. Antiretrovirals for reducing the risk of mother-to-child transmission of HIV infection. Cochrane Database Syst Rev [Internet]. 2007,(1).

11. Guaraldi G; Stentarelli C; Da Silva AD; Luzi K; Neri I; Cellini M; et al. Metabolic alterations in HIV-infected pregnant women: moving to metabolic tailoring of antiretroviral drugs. AIDS Rev. 2014,16(1),1422.

12. da Silva KM; de Sá C dos SC; Carvalho R. Evaluation of motor and cognitive development among infants exposed to HIV. Early Hum Dev. 2017,105,7-10.

13. Springer PE; Slogrove AL; Laughton B; Bettinger JA; Saunders HH; Molteno CD; et al. Neurodevelopmental outcome of HIV-exposed but uninfected infants in the Mother and Infants Health Study, Cape Town, South Africa. Trop Med Int Heal. 2018,23(1),69-78.

14. Wu J; Li J; Li Y; Loo KK; Yang H; Wang Q; et al. Neurodevelopmental outcomes in young children born to HIV-positive mothers in rural Yunnan, China. Pediatr Int. 2018,.
15. Cusick SE; Georgieff MK. The Role of Nutrition in Brain Development: The Golden Opportunity of the \&quot;First 1000 Days\&quot;. J Pediatr. 2016,175,16-21.

16. Sekar V; Kestens D; Spinosa-Guzman S; De Pauw M; De Paepe E; Vangeneugden $\mathrm{T}$; et al. The Effect of Different Meal Types on the Pharmacokinetics of Darunavir (TMC114)/Ritonavir in HIV-Negative Healthy Volunteers. J Clin Pharmacol. 2007,47(4),479-84.

17. Statistics South Africa. Poverty on the rise in South Africa [Internet]. 2017.

18. Slogrove AL; Becquet R; Chadwick EG; Côté HCF; Essajee S; Hazra $\mathrm{R}$; et al. Surviving and Thriving-Shifting the Public Health Response to HIV-Exposed Uninfected Children: Report of the 3rd HIV-Exposed Uninfected Child Workshop. Front Pediatr. 2018,6,157.

19. Western Cape Government D of H. Road to Health Card I Western Cape Government [Internet]. Western Cape Government. 2014

20. Ertem IO; Dogan DG; Gok CG; Kizilates SU; Caliskan A; Atay G; et al. A Guide for Monitoring Child Development in Low- and MiddleIncome Countries. Pediatrics. 2008,121(3),e581-9.

21. WHO |WHO Anthro (version 3.2.2, January 2011) and macros. WHO. 2017.

22. McLennan JE; Gilles FH; Leviton A; Dooling EC. The Developing Human Brain: Growth and Epidemiologic Neuropathology. Elsevier Science; 1983. 43-58 p.

23. Marconi AM; Ronzoni S; Bozzetti P; Vailati S; Morabito A; Battaglia FC. Comparison of fetal and neonatal growth curves in detecting growth restriction. Obstet Gynecol. 2008,112(6),1227-34.

24. Ozturk Ertem I; Krishnamurthy V; Mulaudzi MC; Sguassero Y; Bilik B; Srinivasan R; et al. Validation of the International Guide for Monitoring Child Development demonstrates good sensitivity and specificity in four diverse countries. Acta Paediatr. 2019,108(6),1074-86.

25. SAFOODS. FoodFinder3. South African Medical Research Council;

26. Institute of Medicine (US) Committee to Review Dietary Reference Intakes for; And VD; Ross AC; Taylor CL; Yaktine AL; Valle HB Del. Dietary Reference Intakes for Calcium and Vitamin D [Internet]. Dietary Reference Intakes for Calcium and Vitamin D. National Academies Press (US); 2011

27. Mchiza Z; Steyn N; Hill J; Kruger A; Schönfeldt H; Nel J; et al. A Review of Dietary Surveys in the Adult South African Population from 2000 to 2015. Nutrients. 2015,7(9),8227-50.

28. Kennedy G; Ballard T; Dop MC (Marie C; European Union. Guidelines for measuring household and individual dietary diversity [Internet] Food and Agriculture Organization of the United Nations; 2011. $53 \mathrm{p}$.

29. Labadarios D; Steyn NP; Nel J. How diverse is the diet of adult South Africans? Nutr J. 2011,10(1),33.

30. Muenchhoff M; Healy M; Singh R; Roider J; Groll A; Kindra C; et al. Malnutrition in HIV-Infected Children Is an Indicator of Severe Disease with an Impaired Response to Antiretroviral Therapy. AIDS Res Hum Retroviruses. 2018,34(1),46-55.

31. Rytter MJH; Kolte L; Briend A; Friis H; Christensen VB. The immune system in children with malnutrition--a systematic review. PLoS One. 2014,9(8),e105017.

32. Munthali T; Jacobs C; Sitali L; Dambe R; Michelo C. Mortality and morbidity patterns in under-five children with severe acute malnutrition (SAM) in Zambia: a five-year retrospective review of hospital-based records (2009-2013). Arch Public Health. 2015,73(1),23.

33. Prendergast AJ; Humphrey JH. The stunting syndrome in developing countries. Paediatr Int Child Health. 2014,34(4),250-65.

34. Prendergast AJ; Chasekwa B; Rukobo S; Govha M; Mutasa K; Ntozini $\mathrm{R}$; et al. Intestinal Damage and Inflammatory Biomarkers in Human Immunodeficiency Virus (HIV)-Exposed and HIV-Infected Zimbabwean Infants. J Infect Dis. 2017,216(6),651-61. 
35. Feucht UD; Van Bruwaene L; Becker PJ; Kruger M. Growth in HIVinfected children on long-term antiretroviral therapy. Trop Med Int Heal. 2016,21(5),619-29.

36. Jain V; Singhal A. Catch up growth in low birth weight infants: Striking a healthy balance. Rev Endocr Metab Disord. 2012,13(2),141-7.

37. Leitner Y; Fattal-Valevski A; Geva R; Eshel R; Toledano-Alhadef H; Rotstein $\mathrm{M}$; et al. Neurodevelopmental outcome of children with intrauterine growth retardation: a longitudinal, 10-year prospective study. J Child Neurol. 2007,22(5),580-7.

38. Olearo E; Oberto M; Oggè G; Botta G; Pace C; Gaglioti P; et al. Thymic volume in healthy, small for gestational age and growth restricted fetuses. Prenat Diagn. 2012,32(7),662-7.

39. Tröger B; Müller T; Faust K; Bendiks M; Bohlmann MK; Thonnissen $\mathrm{S}$; et al. Intrauterine Growth Restriction and the Innate Immune System in Preterm Infants of $=32$ Weeks Gestation. Neonatology. 2013,103(3),199-204.

40. Barker D; Eriksson J; Forsén T; Osmond C. Fetal origins of adult disease: strength of effects and biological basis. Int $\mathrm{J}$ Epidemiol. 2002,31(6), 1235-9.

41. Olagbuji BN; Ezeanochie MC; Ande AB; Oboro VO. Obstetric and perinatal outcome in HIV positive women receiving HAART in urban Nigeria. Arch Gynecol Obstet. 2010,281(6),991-4.

42. Yan X; Zhao X; Li J; He L; Xu M. Effects of early-life malnutrition on neurodevelopment and neuropsychiatric disorders and the potential mechanisms. Prog Neuro-Psychopharmacology Biol Psychiatry. 2018,83,64-75.

43. Habib N; Daltveit A; Bergsjø P; Shao J; Oneko O; Lie R. Maternal HIV status and pregnancy outcomes in northeastern Tanzania: a registrybased study. BJOG An Int J Obstet Gynaecol. 2008,115(5),616-24.

44. Abubakar A; Holding P; Van Baar A; Newton CRJC; Van de Vijver FJR; Espy KA. The performance of children prenatally exposed to HIV on the A-not-B task in Kilifi, Kenya: a preliminary study. Int J Environ Res Public Health. 2013,10(9),4132-42.

45. Chaudhury S; Williams PL; Mayondi GK; Leidner J; Holding P; Tepper $\mathrm{V}$; et al. Neurodevelopment of HIV-Exposed and HIV-Unexposed Uninfected Children at 24 Months. Pediatrics. 2017,140(4),e20170988.

46. Alimenti A; Forbes JC; Oberlander TF; Money DM; Grunau RE; Papsdorf MP; et al. A prospective controlled study of neurodevelopment in HIV-uninfected children exposed to combination antiretroviral drugs in pregnancy. Pediatrics. 2006,118(4),e1139-45.

47. Tran LT; Roos A; Fouche J-P; Koen N; Woods RP; Zar HJ; et al. White Matter Microstructural Integrity and Neurobehavioral Outcome of HIVExposed Uninfected Neonates. Medicine (Baltimore). 2016,95(4),e2577.

48. Bravi F; Wiens F; Decarli A; Dal Pont A; Agostoni C; Ferraroni M. Impact of maternal nutrition on breast-milk composition: a systematic review. Am J Clin Nutr. 2016,104(3),646-62.

49. Fadilah A; Musson R; Ong MT; Desurkar AV; Mordekar SR. Vitamin B12 deficiency in infants secondary to maternal deficiency: A case series of seven infants. Eur J Paediatr Neurol EJPN [Internet]. $2017,21, \mathrm{e} 3$.

50. WHO | Breast is always best, even for HIV-positive mothers. WHO. 2011.

51. WHO | Exclusive breastfeeding for six months best for babies everywhere. WHO. 2011,

52. Victora CG; Bahl R; Barros AJD; França GVA; Horton S; Krasevec J; et al. Breastfeeding in the 21st century: epidemiology, mechanisms, and lifelong effect. Lancet. 2016,387(10017),475-90.

53. Webb-Girard A; Cherobon A; Mbugua S; Kamau-Mbuthia E; Amin A; Sellen DW. Food insecurity is associated with attitudes towards exclusive breastfeeding among women in urban Kenya. Matern Child Nutr. 2012,8(2),199-214.
54. Jama NA; Wilford A; Masango Z; Haskins L; Coutsoudis A; Spies L; et al. Enablers and barriers to success among mothers planning to exclusively breastfeed for six months: a qualitative prospective cohort study in KwaZulu-Natal, South Africa. Int Breastfeed J. 2017,12(1),43.

55. Lee S; Kelleher SL. Biological underpinnings of breastfeeding challenges: the role of genetics, diet, and environment on lactation physiology. Am J Physiol Endocrinol Metab. 2016,311(2),E405-22.

56. Hunt KM; Foster JA; Forney LJ; Schütte UME; Beck DL; Abdo Z; et al. Characterization of the Diversity and Temporal Stability of Bacterial Communities in Human Milk. Zilberstein D, editor. PLoS One. 2011,6(6),e21313.

57. Cabrera-Rubio R; Collado MC; Laitinen K; Salminen S; Isolauri E; Mira A. The human milk microbiome changes over lactation and is shaped by maternal weight and mode of delivery. Am J Clin Nutr. 2012,96(3),544-51.

58. Shapiro RL; Lockman S; Kim S; Smeaton L; Rahkola JT; Thior I; et al. Infant morbidity, mortality, and breast milk immunologic profiles among breast-feeding HIV-infected and HIV-uninfected women in Botswana. J Infect Dis [Internet]. 2007,196(4),562-9.

59. Pedersen SH; Wilkinson AL; Andreasen A; Kinung'hi SM; Urassa M; Michael $D$; et al. Longitudinal analysis of mature breastmilk and serum immune composition among mixed HIV-status mothers and their infants. Clin Nutr. 2016,35(4),871-9.

60. Kuhn L; Kim H-Y; Hsiao L; Nissan C; Kankasa C; Mwiya M; et al. Oligosaccharide Composition of Breast Milk Influences Survival of Uninfected Children Born to HIV-Infected Mothers in Lusaka, Zambia. J Nutr. 2015,145(1),66-72.

61. Chowdhury R; Sinha B; Sankar MJ; Taneja S; Bhandari N; Rollins N; et al. Breastfeeding and maternal health outcomes: a systematic review and meta-analysis. Acta Paediatr. 2015,104(467),96-113.

62. Ballard O; Morrow AL. Human milk composition: nutrients and bioactive factors. Pediatr Clin North Am. 2013,60(1),49-74.

63. UNAIDS. The Gap Report. Geneva; 2014

64. 'Jooste P; Zimmermann M. Progress towards eliminating iodine deficiency in South Africa. South African J Clin Nutr. 2008,21(1),814.

65. `Jiang NM, Tofail F, Ma JZ, et al. Early Life Inflammation and Neurodevelopmental Outcome in Bangladeshi Infants Growing Up in Adversity. Am J Trop Med Hyg 2017;97:974-9.

66. ${ }^{\ddagger}$ Veenstra M, Byrd DA, Inglese M, et al. CCR2 on Peripheral Blood CD14+CD16+ Monocytes Correlates with Neuronal Damage, HIVAssociated Neurocognitive Disorders, and Peripheral HIV DNA: reseeding of CNS reservoirs? J Neuroimmune Pharmacol 2019;14:120-33.

${ }^{\dagger}$ Cited in Table 1 legend

${ }^{\ddagger}$ Cited in Supplementary Table S1 and S2 legends 


\section{Percent estimated average requirements (EARs) met}
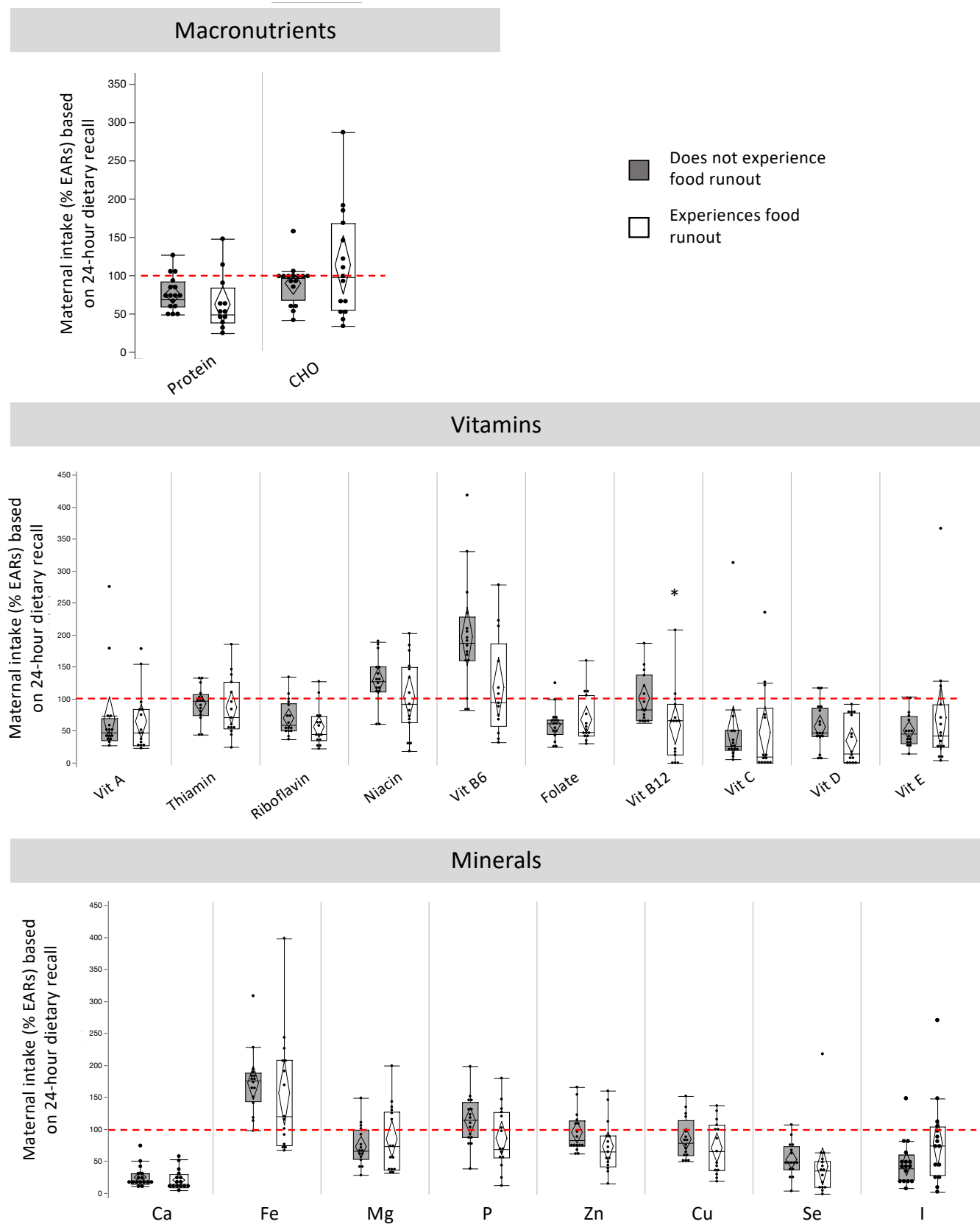

Supplementary figure S1. Maternal intake of estimated average requirements for macronutrients, vitamins and minerals for mothers who report experiencing food runout (compared to not). Maternal reports of food insecurity did not associate with intake levels of macronutrients or minerals. Maternal reports of experiencing food runout associated with lower intake of vitamin B12 [B; $A d j P=0.20, p=0.01])$. Many women, irrespective of food security reports, are at risk of inadequate macronutrient, vitamin and mineral intakes. Percent intake of EARs for nutrients were calculated for lactating women 14-18, 19-30 or 31-50 years of age [26]. No EARs are available for total fat. Calculations for EAR for total protein considered maternal weight at time of dietary recall. Data are \% intake of EAR reported in maternal dietary recall for macronutrients (quartiles, median lines and 95\% confidence diamonds, ${ }^{*} \mathrm{p}<0.05$ [ANOVA for normal distribution/equal variance; Kruskal-Wallis/Wilcoxon test for non-parametric data; or Welch's test for normal data/unequal variance]). $\mathrm{CHO}=$ carbohydrates. 


\section{Percent estimated average requirements (EARs) met}
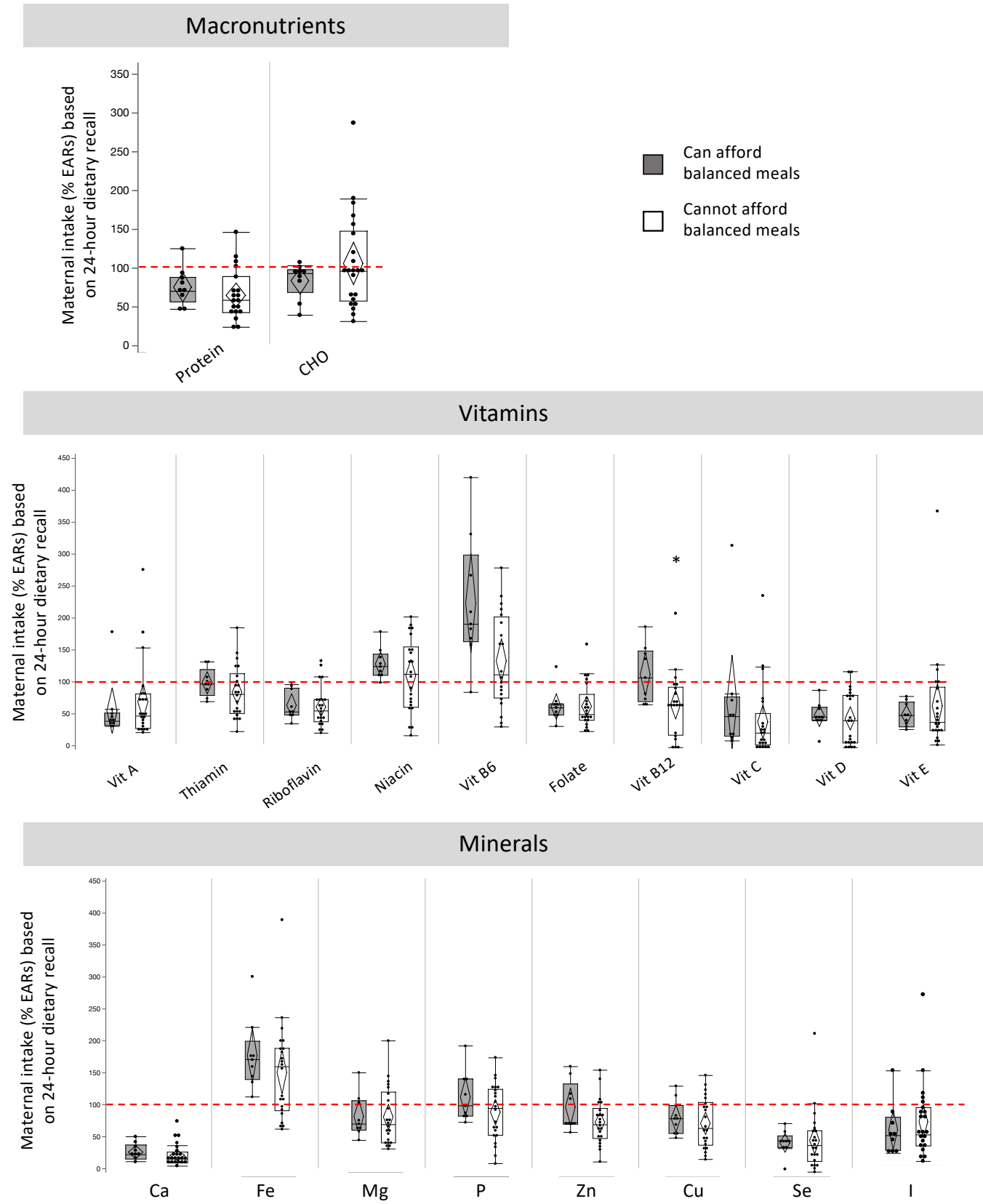

Supplementary figure S2. Maternal intake of estimated average requirements for macronutrients, vitamins and minerals for mothers who report inability to afford balanced meals (compared to not). Maternal reports of food insecurity did not associate with intake levels of macronutrients or minerals. Maternal reports of inability to afford balanced meals associated with lower intake of vitamin $B 12$ (C; AdjP=0.05, $p=0.04)$. Many women, irrespective of food security reports, are at risk of inadequate macronutrient, vitamin and mineral intakes. Percent intake of EARs for nutrients were calculated for lactating women 14-18, 19-30 or 31-50 years of age [26]. No EARs are available for total fat. Calculations for EAR for total protein considered maternal weight at time of dietary recall. Data are \% intake of EAR reported in maternal dietary recall for macronutrients (quartiles, median lines and $95 \%$ confidence diamonds, ${ }^{*} p<0.05$ [ANOVA for normal distribution/equal variance; Kruskal-Wallis/Wilcoxon test for non-parametric data; or Welch's test for normal data/unequal variance]). $\mathrm{CHO}=$ carbohydrates. 
A
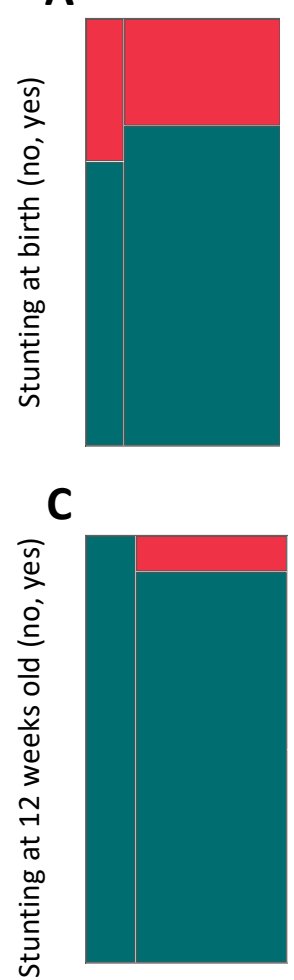

HUU, HEU
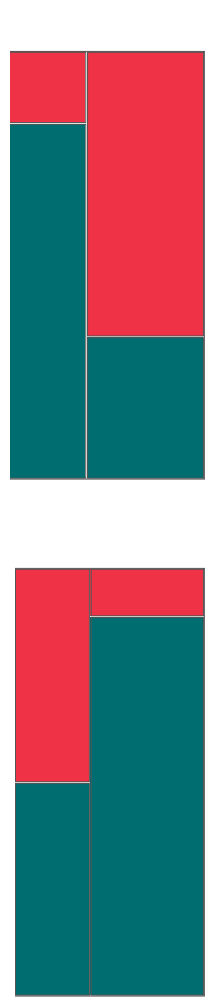

HUU, HEU

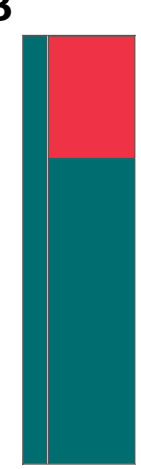

D

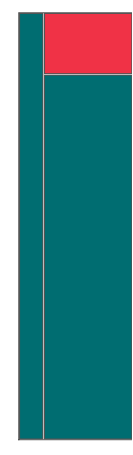

HUU, HEU
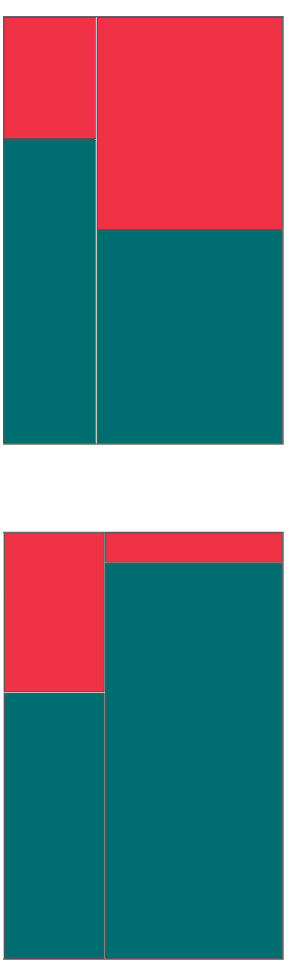

HUU, HEU
NO

YES

Experiences food runout
YES

NO

Can afford balanced meals
Stunting

No stunting

Supplementary figure S3. Cooccurrence of maternal HIV and food insecurity does not influence risk of stunting at birth. Maternal reports of experiencing food runout or inability to afford balanced meals (compared to not experiences these circumstances) does not influence risk of stunting at birth for HEU compared to HUU infants (A-D). Mosaic plots are proportion (\%) of HUU or HEU infants who have stunting (<-2 SD length-for-age standardised according to WHO child growth standards [21]) at birth and 12 weeks old. GMCD = Guide for monitoring child development. HUU = HIVunexposed, uninfected infant; HEU = HIV-exposed, uninfected infant. 
A

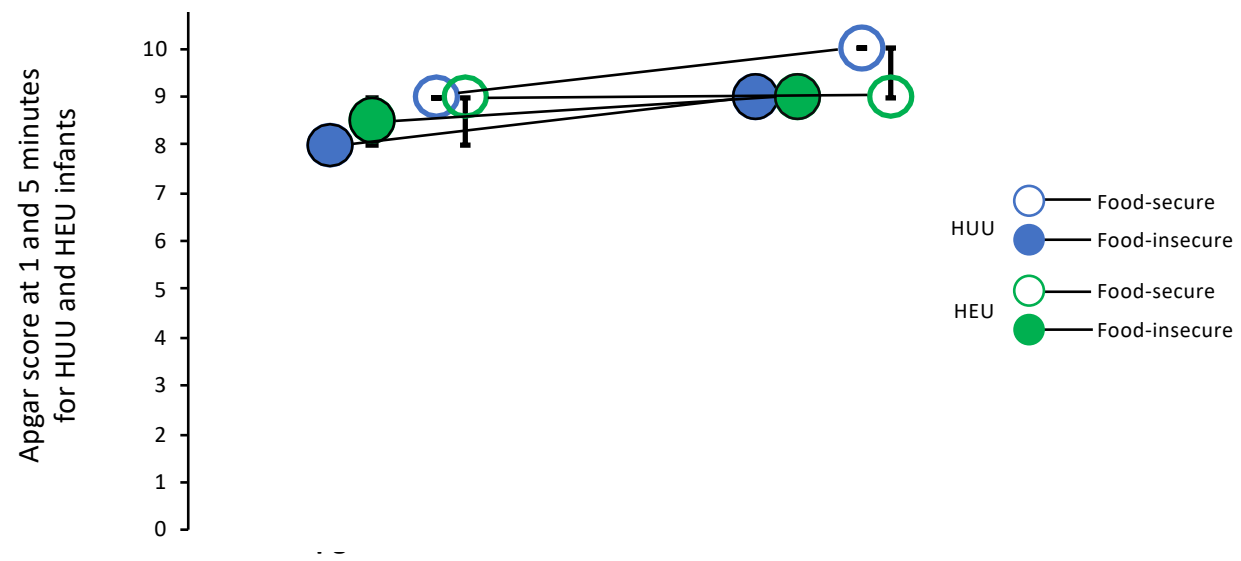

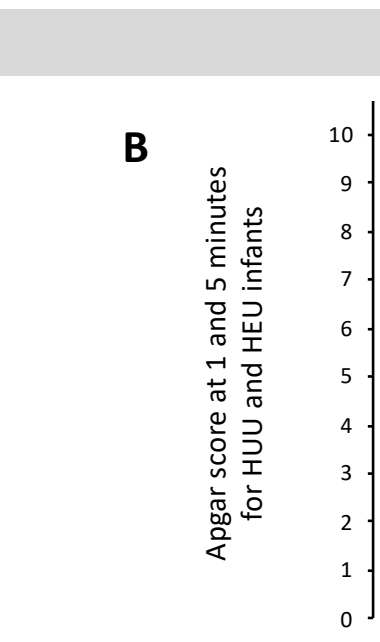

Food Runout - Experienced

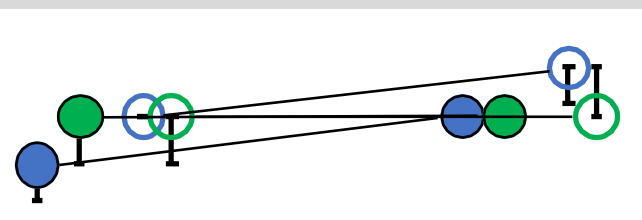

HUU

HEU

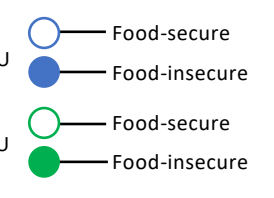

Apgar $1 \mathrm{~min}$

Apgar $5 \mathrm{~min}$

\section{Afford balanced meals}

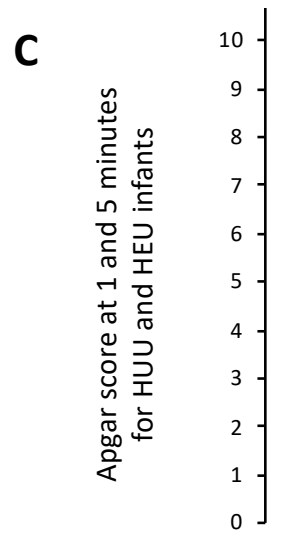
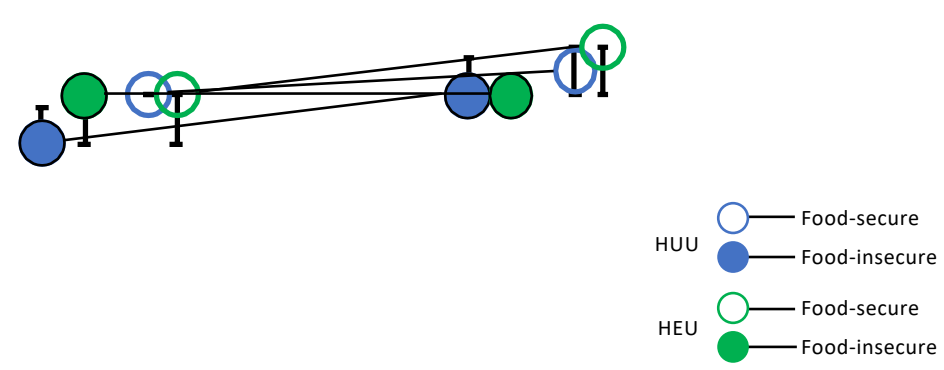

Supplementary figure S4. Apgar scores at one and five minutes stratified by HIV exposure status and reports of food insecurity. Apgar scores at one and five minutes after birth were not different between HUU ( $n=10)$ and HEU $(n=21)$ infants, irrespective of household reports of food (in)security (A-C, ANCOVA, p>0.05). Data are group median (IQR) for measured Apgar scores at one and five minutes postpartum. HUU = HIV-unexposed, uninfected infant; HEU = HIV-exposed, uninfected infant. 


\section{Food Runout - Worry}

A

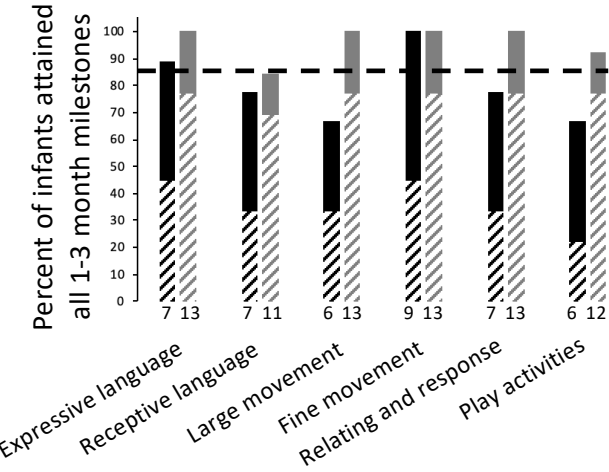

B

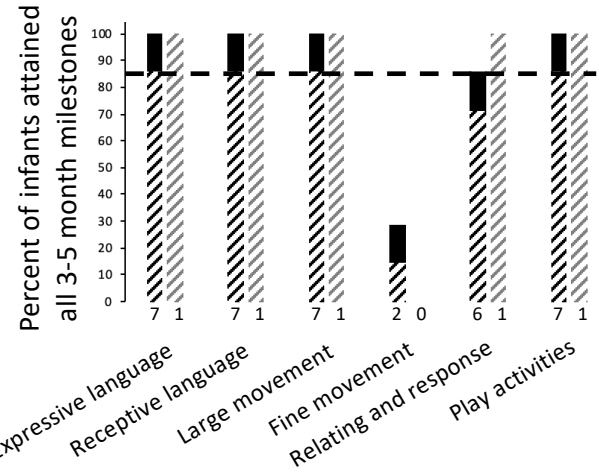

Food Runout - Experienced

C
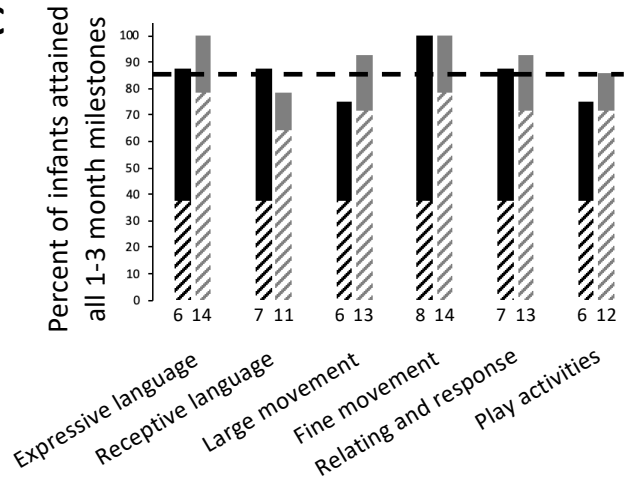

D

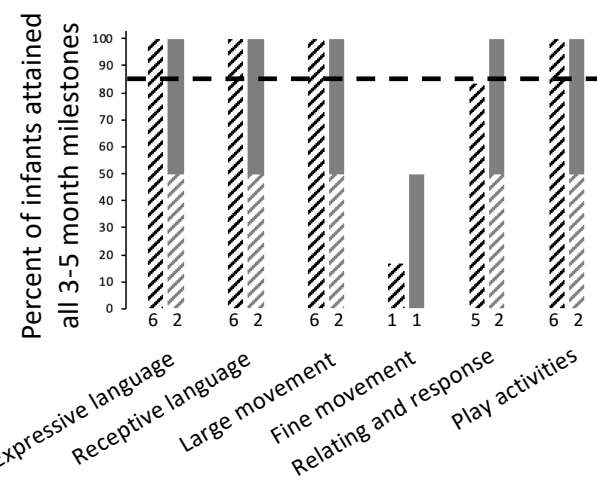

Afford balanced meals

E

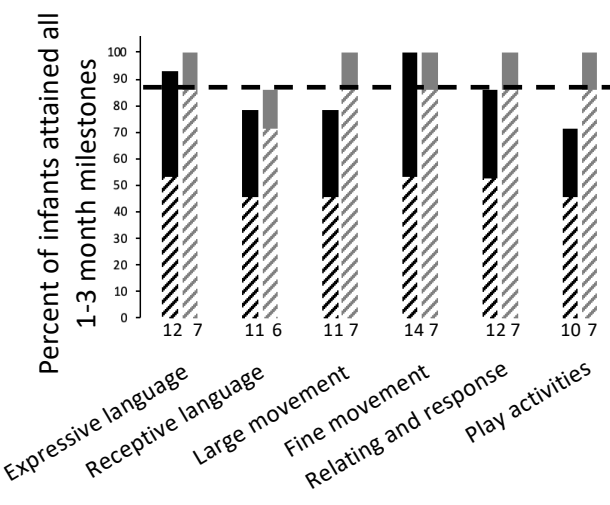

F $\overline{\bar{\pi}}$

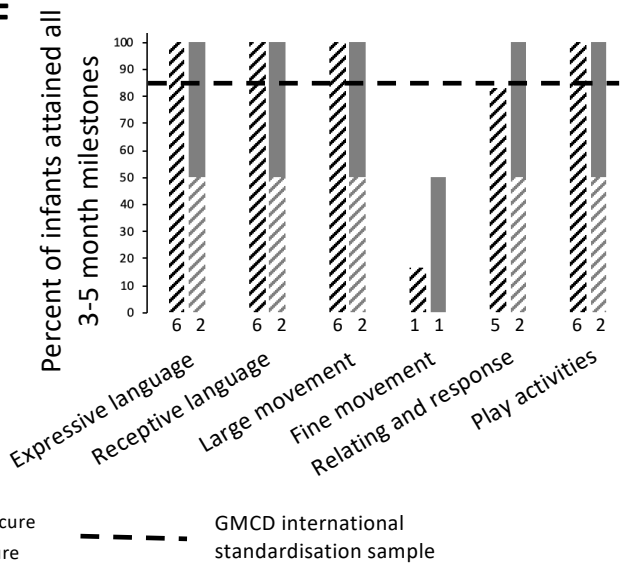

Supplementary figure S5. Food insecurity associates with low attainment of GMCD milestones for HUU and HEU infants. Infants whose mothers reported household food insecurity did not attain 1-3 month GMCD milestones (A, C, E) for receptive language, large movement, relating and response behaviour or play activities, or 3-5 month $G M C D$ milestones $(B, D, F)$ for fine movement or relating and response behaviour in the same proportion as the international standardization sample. Maternal reports of food insecurity did not associate with risk of not attaining all 1-3 month or 3-5 month GMCD milestones (A-F, [p>0.05], Fisher's exact 2-Tail). Data are proportion (\%) of infants who attained all age-appropriate GMCD milestones. The horizontal dotted line represents the GMCD standardised international sample proportion $(85 \%)$ of infants who attained all milestones in that age category, when they were in that age range. The numbers underneath the bars represent the number of infants attaining all milestones for each milestone. GMCD $=$ Guide for monitoring child development; HUU = HIV-unexposed, uninfected infant; HEU = HIV-exposed, uninfected infant. 
Supplementary table S1. Final ANCOVA models for analysis of infant anthropometry and Apgar scores at birth for infants who were exposed to food insecure conditions compared to those who were not.

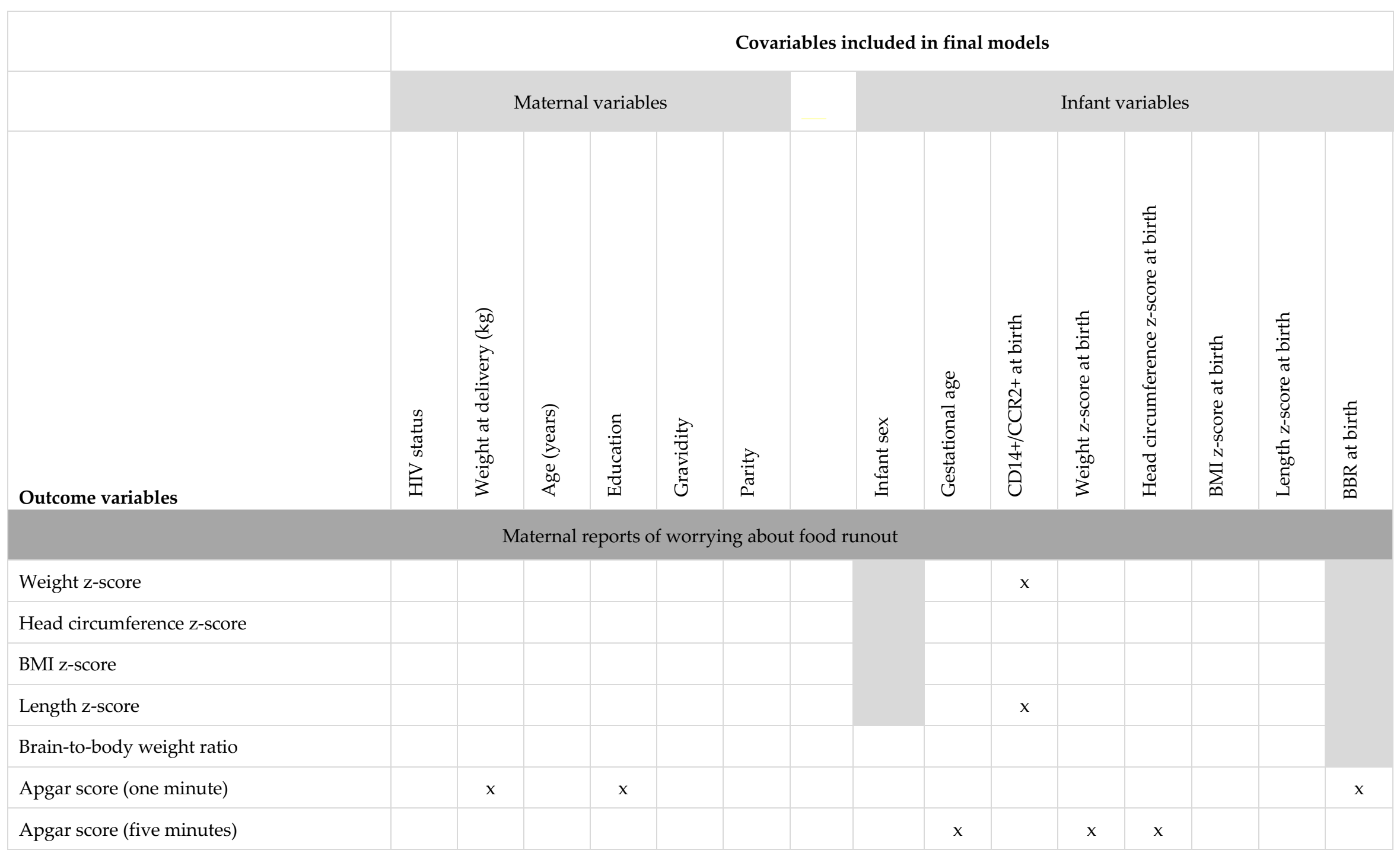




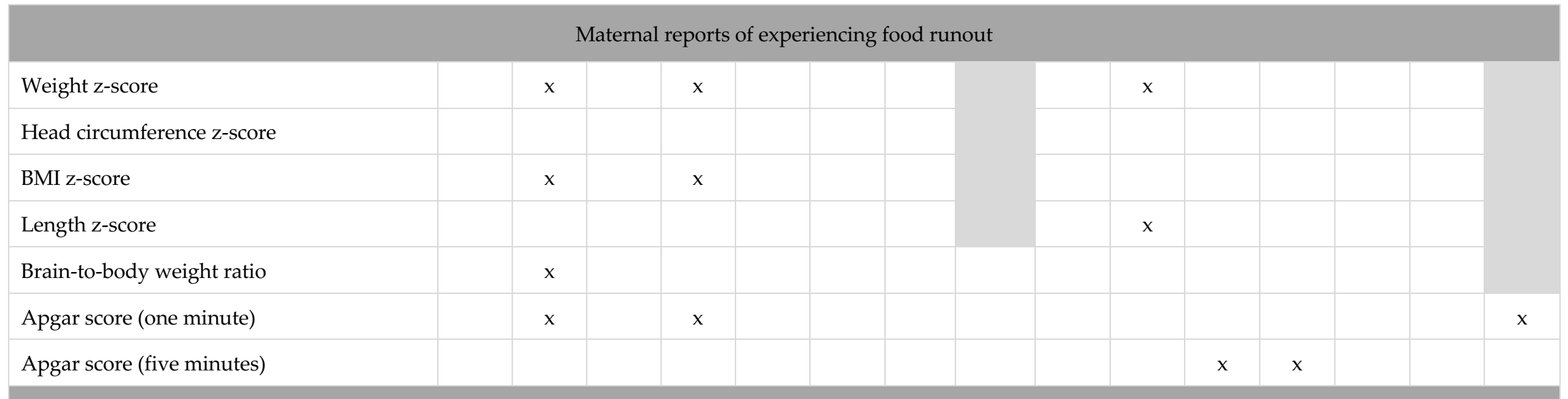

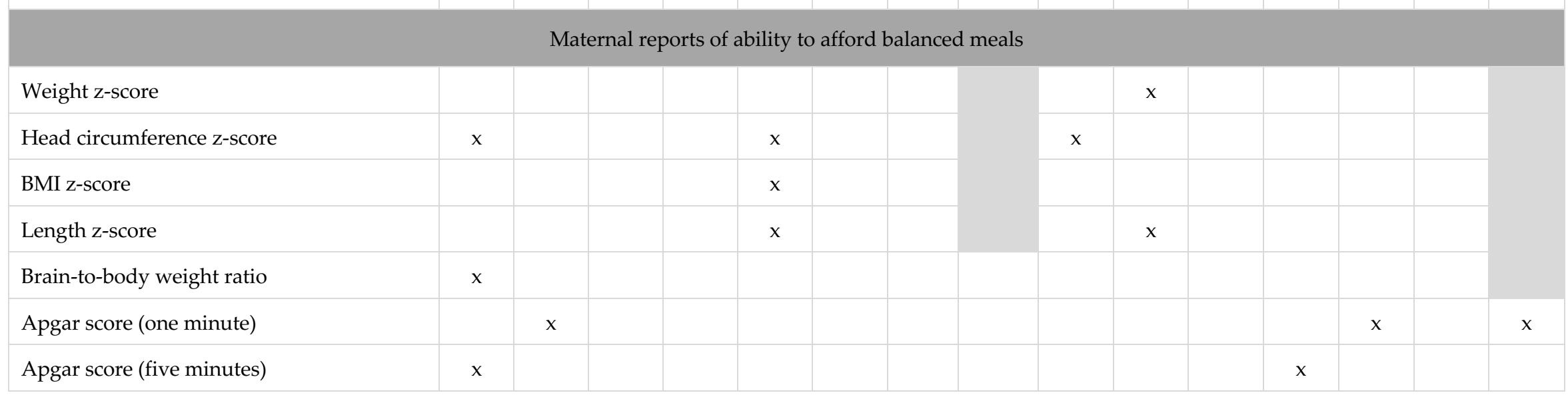

Boxes marked ' $x$ ' indicate that the variable was included in the final model, and covariates shaded grey were not considered as potential confounders for the respective outcome variable. We considered infant CCR2 expression on total monocytes a potential confounding variable, as increased monocyte activation in infants has been associated with poorer neurodevelopmental outcomes in the first two years of life [65], and increased CCR2 expression on CD14+ monocytes is a known risk factor for increased neuro-inflammation and disorder in in adults with HIV [66]. BBR = brain-to-body weight ratio. 
Supplementary table S2. Final ANCOVA models for analysis of infant anthropometry and neurodevelopmental outcome at 12 weeks postpartum for infants who were exposed to food insecure conditions compared to those who were not.

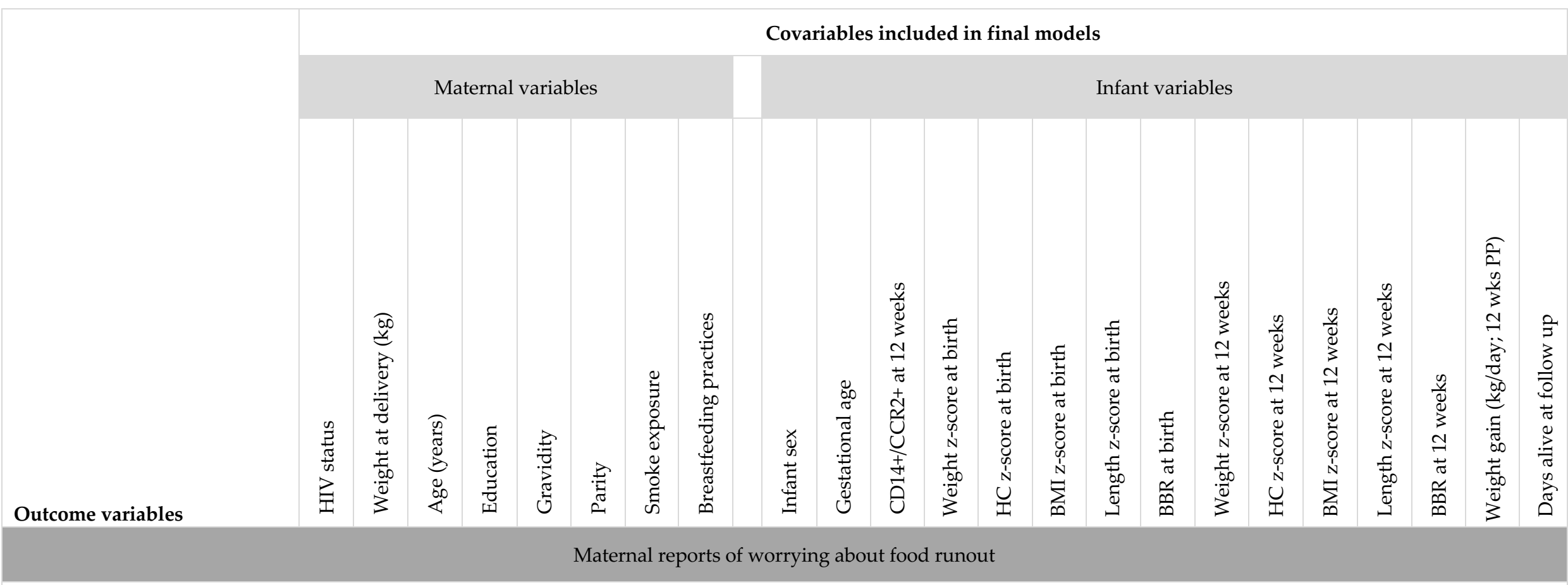

\section{Anthropometry at 12 weeks PP}

Weight z-score

HC z-score

BMI z-score

Length z-score

BBR

Weight gain (kg/day; birth-12

wks PP)

\section{GMCD milestones attained (n)}

Expressive language

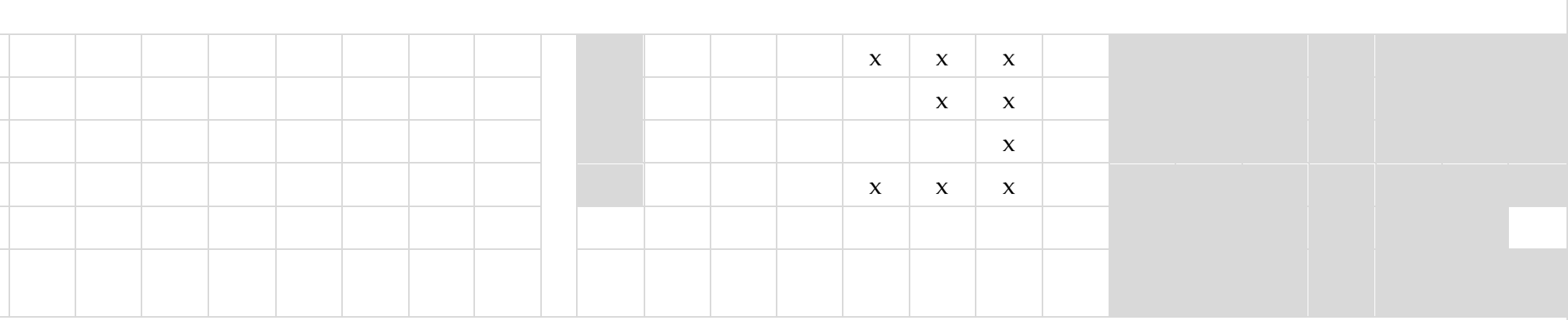


Receptive language

Fine movement

Large movement

Play activities

Relating/response

\begin{tabular}{|c|c|c|c|c|c|}
\hline & $\mathrm{x}$ & & & & \\
\hline $\mathrm{x}$ & $\mathrm{x}$ & & & $\mathrm{x}$ \\
\hline $\mathrm{x}$ & & $\mathrm{x}$ & & $\mathrm{x}$ & \\
\hline
\end{tabular}

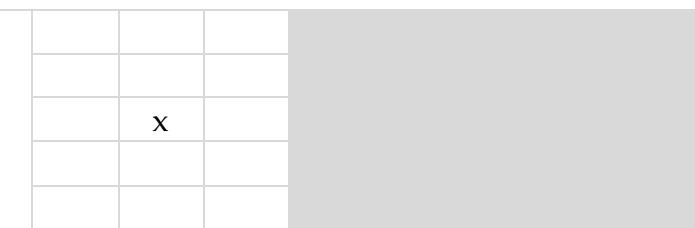

\begin{tabular}{|l|l|l|l|l|l|}
\hline & & $\mathrm{x}$ & & & $\mathrm{x}$ \\
\hline & $\mathrm{x}$ & $\mathrm{x}$ & & & \\
\hline $\mathrm{x}$ & $\mathrm{x}$ & & $\mathrm{x}$ & & $\mathrm{x}$ \\
\hline $\mathrm{x}$ & $\mathrm{x}$ & $\mathrm{x}$ & $\mathrm{x}$ & & \\
\hline & $\mathrm{x}$ & & $\mathrm{x}$ & $\mathrm{x}$ & $\mathrm{x}$ \\
\hline
\end{tabular}

Maternal reports of experiencing food runout

\section{Anthropometry at 12 weeks PP}

Weight z-score

$\mathrm{HC}$ z-score

BMI z-score

Length z-score

BBR

Weight gain (kg/day; birth-12 wks PP)

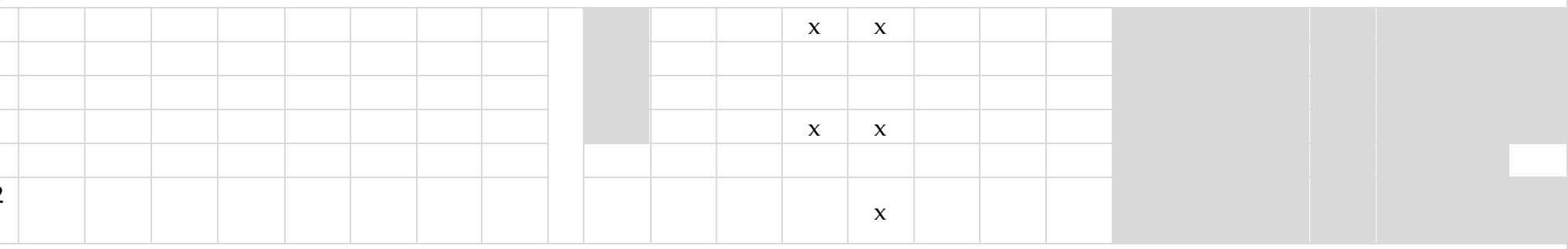

\section{GMCD milestones attained (n)}

Expressive language

Receptive language

Fine movement

Large movement

Play activities

Relating/response

\begin{tabular}{|c|c|c|c|c|c|c|}
\hline & & $x$ & & $x$ \\
\hline & $x$ & & & $x$ \\
\hline & $x$ & & & & \\
\hline & & & & & \\
\hline
\end{tabular}

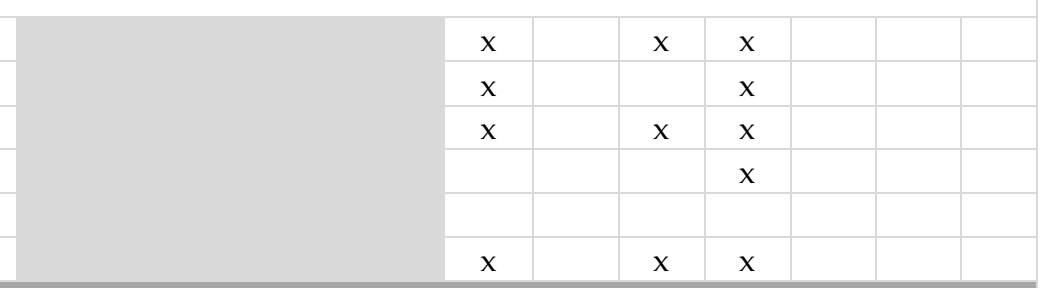

Maternal reports of ability to afford balanced meals

\section{Anthropometry at 12 weeks PP}

Weight z-score

$\mathrm{HC}$ z-score

BMI z-score

Length z-score

BBR

Weight gain (kg/day; birth-12

wks PP)

\begin{tabular}{|l|l|l|l|l|l|}
\hline & & $x$ & $x$ & \\
\hline & & $x$ & $x$ & \\
\hline & $x$ & $x$ & & \\
\hline & & & & & \\
\hline & & & & & \\
\hline
\end{tabular}

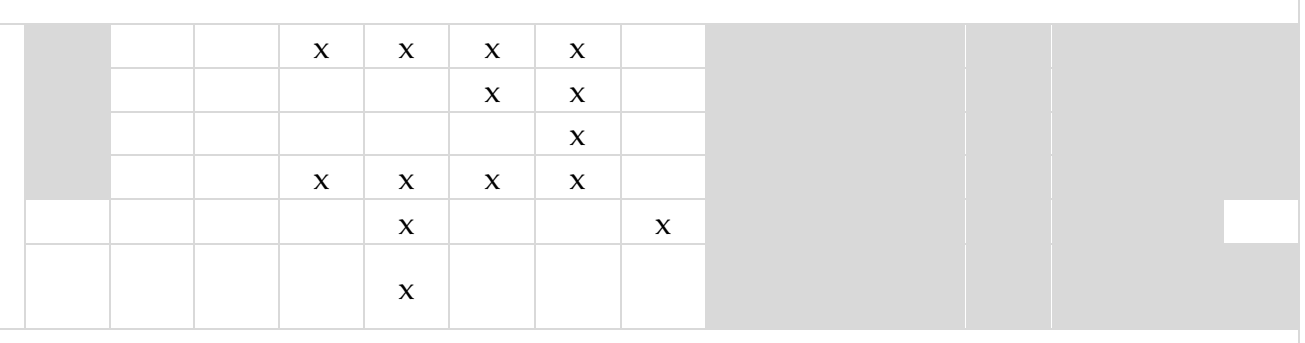

\section{GMCD milestones attained (n)}




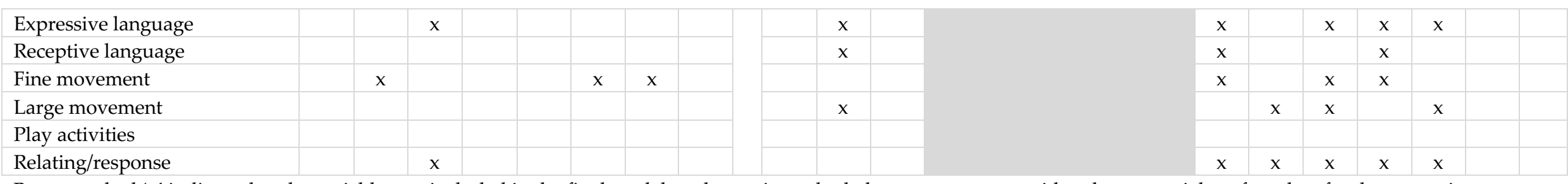

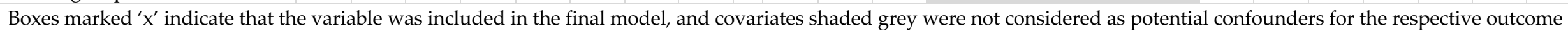

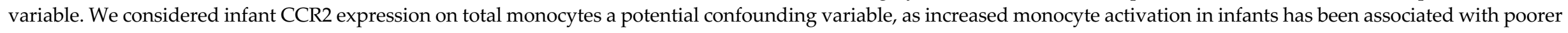

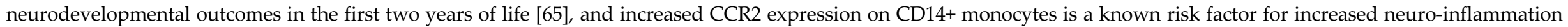

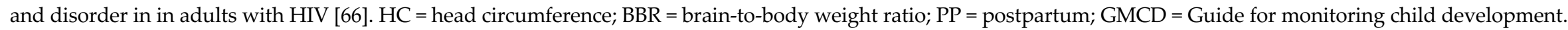


Supplementary Table S3. Maternal and infant cohort characteristics. Maternal characteristics

\begin{tabular}{|c|c|c|c|}
\hline & $\begin{array}{c}\text { HIV-uninfected } \\
\mathrm{n}=10\end{array}$ & $\begin{array}{c}\text { HIV-infected } \\
\quad \mathrm{n}=21\end{array}$ & p value \\
\hline Weight at delivery (kg) & $60.0(53.0,80.0)$ & $63.5(57.3,72.0)$ & NS \\
\hline Age at delivery (years) & $28.4 \pm 8.96$ & $30.6 \pm 6.07$ & NS \\
\hline Gravidity (n) & $3.00(2.00,3.00)$ & $2.00(1.00,4.00)$ & NS \\
\hline Parity (n) & $2.00(1.50,3.00)$ & $2.00(1.00,3.25)$ & NS \\
\hline Level of education (n) & & & NS \\
\hline Junior & 1 & 5 & \\
\hline Secondary & 8 & 14 & \\
\hline Post-secondary & 1 & 1 & \\
\hline Not indicated & - & 1 & \\
\hline \multicolumn{4}{|l|}{ Current ART (n) } \\
\hline TDF, FTC, EFV & - & 19 & \\
\hline $\mathrm{AZT}, 3 \mathrm{TC}, \mathrm{LPV} / \mathrm{r}$ & - & 1 & \\
\hline None & - & 1 & \\
\hline \multicolumn{4}{|l|}{ Infant characteristics } \\
\hline & $\begin{array}{l}\text { HUU } \\
n=10\end{array}$ & $\begin{array}{l}\text { HEU } \\
n=21\end{array}$ & $p$ value \\
\hline \multicolumn{4}{|l|}{ Infant birth outcomes } \\
\hline Infant sex (\% male) & 50.0 & 33.3 & NS \\
\hline Gestational age at delivery (weeks) & $37.9 \pm 1.37$ & $38.9 \pm 1.80$ & NS \\
\hline$<37$ weeks GA (n) & 1 & 2 & NS \\
\hline Stunting at birth* (n [\%])) & $2(22.2)$ & $9(42.9)$ & NS \\
\hline \multicolumn{4}{|l|}{ Infant outcomes at 12 weeks PP } \\
\hline EBF at follow up (n [\%]) & $4(40.0)$ & $14(81.0)$ & NS \\
\hline Infant age at follow up (weeks) & $10.4(10.1,12.1)$ & $12.0(10.1,1.33)$ & NS \\
\hline Stunting at 12 weeks postpartum ${ }^{1}(\mathrm{n}[\%])$ & $3(30.0)$ & $2(9.52)$ & NS \\
\hline
\end{tabular}

Data from mother-infant dyads that attended follow up are mean \pm SD or median (IQR) and $p$ values are from univariate analysis (Kruskal-Wallis/Wilcoxon test for non-parametric data; ANOVA for normal data with equal variance). Differences in household food security circumstances for women living with and without HIV, proportions for infant sex, $<37$ weeks gestational age, \% EBF (exclusively breastfed) at follow up, and risk of stunting for HUU vs. HEU infants were assessed by Fisher's exact test (2-tail). ${ }^{1}$ Stunting is determined by <-2 SD length-for-age standardised z-score according to WHO child growth standards [21]. ART = antiretroviral therapy. $\mathrm{NS}=$ non-significant; $\mathrm{TDF}=$ Tenofovir; $\mathrm{FTC}=$ emtricitabine; $\mathrm{EFV}=$ efavirenz; $\mathrm{AZT}=$ azidothymidine; $3 \mathrm{TC}=$ lamivudine; $\mathrm{LPV} / \mathrm{r}=$ ritonavir-boosted lopinavir; $\mathrm{HUU}=\mathrm{HIV}$-unexposed, uninfected infant; HEU = HIV-exposed, uninfected infant; $\mathrm{GA}=$ Gestational age; $\mathrm{EBF}=$ Exclusive breastfeeding. 


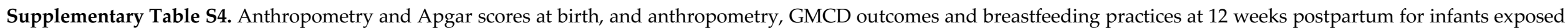
to food-insecure conditions compared to those who were not.

\begin{tabular}{|c|c|c|c|c|c|c|c|c|c|}
\hline & \multicolumn{3}{|c|}{ Do you worry about food runout? } & \multicolumn{3}{|c|}{ Do you experience food runout? } & \multicolumn{3}{|c|}{ Are you able to afford balanced meals? } \\
\hline & NO & YES & \multirow{2}{*}{ p value } & NO & YES & \multirow{2}{*}{ p value } & YES & NO & \multirow{2}{*}{ p value } \\
\hline & $\mathrm{n}=14$ & $\mathrm{n}=17$ & & $\mathrm{n}=16$ & $\mathrm{n}=15$ & & $\mathrm{n}=9$ & $n=22$ & \\
\hline Gestational age at delivery (weeks) & $38.8 \pm 1.81$ & $38.4 \pm 1.66$ & NS & $38.6 \pm 1.79$ & $38.5 \pm 1.69$ & NS & $38.2 \pm 1.99$ & $38.7 \pm 1.62$ & NS \\
\hline EBF at 12 weeks PP (n [\%]) & $11(78.6)$ & $7(41.4)$ & NS & $13(81.3)$ & $5(33.3)$ & 0.01 & $8(88.9)$ & $9(42.9)$ & 0.04 \\
\hline \multicolumn{10}{|c|}{ Infant anthropometry and Apgar at birth* } \\
\hline Head circumference z-score & $-1.49 \pm 0.99$ & $-0.81 \pm 1.46$ & NS & $-1.39 \pm 0.96$ & $-0.82 \pm 1.56$ & NS & $-1.71 \pm 1.14$ & $-0.87 \pm 1.30$ & NS \\
\hline Weight z-score & $-0.59 \pm 1.00$ & $-1.08 \pm 1.10$ & NS & $-0.59 \pm 0.94$ & $-1.14 \pm 1.15$ & NS & $-0.83 \pm 0.93$ & $-0.87 \pm 1.14$ & NS \\
\hline Length z-score & $-1.20 \pm 1.41$ & $-1.05 \pm .2 .10$ & NS & $-1.21 \pm 1.36$ & $-1.02 \pm 2.20$ & NS & $-0.98 \pm 1.35$ & $-1.18 \pm 1.99$ & NS \\
\hline BMI z-score & $-0.02 \pm 1.81$ & $-0.94 \pm 1.64$ & NS & $-0.02 \pm 1.68$ & $-1.06 \pm 1.69$ & NS & $-0.64 \pm 1.61$ & $-0.50 \pm 1.83$ & NS \\
\hline Brain-to-body weight ratio & $9.65(8.90,10.3)$ & $10.4(9.70,12.0)$ & 0.04 & $9.78(8.95,10.4)$ & $10.5(9.54,12.0)$ & NS & $9.54(8.97,10.4)$ & $10.1(9.38,11.4)$ & NS \\
\hline Apgar 1-minute score & $9.00(8.75,9.00)$ & $8.00(8.00,9.00)$ & NS & $9.00(8.25,9.00)$ & $8.00(8.00,9.00)$ & NS & $9.00(8.50,9.00)$ & $8.00(8.00,9.00)$ & NS \\
\hline Apgar 5-minute score & $10.0(9.00,10.0)$ & $9.00(9.00,9.00)$ & 0.02 & $9.50(9.00,10.0)$ & $9.00(9.00,9.00)$ & NS & $10.0(9.00,10.0)$ & $9.00(9.00,9.00)$ & NS \\
\hline \multicolumn{10}{|c|}{ Infant anthropometry in infants aged 12 weeks ${ }^{1}$} \\
\hline Weight z-score & $-0.08(-0.77,0.23)$ & $-0.45(-1.26,0.14)$ & NS & $-0.08(-0.66,0.26)$ & $-0.46(-1.47,0.11)$ & NS & $-0.41(-0.83,0.38)$ & $-0.13(-1.12,0.14)$ & NS \\
\hline Length z-score & $-0.84 \pm 0.64$ & $-1.52 \pm 0.99$ & NS & $-0.85 \pm 0.61$ & $-1.60 \pm 1.02$ & NS & $-1.14(-1.45,-0.69)$ & $-1.02(-1.80,-0.38)$ & NS \\
\hline BMI z-score & $0.37 \pm 0.96$ & $0.19 \pm 1.74$ & NS & $0.41 \pm 0.96$ & $0.11 \pm 1.82$ & NS & $0.64 \pm 1.00$ & $0.12 \pm 1.55$ & NS \\
\hline Brain-to-body weight ratio & $7.40(6.84,7.74)$ & $7.61(7.11,7.91)$ & NS & $7.21(6.88,7.69)$ & $7.72(7.29,8.12)$ & NS & $7.48(7.05,7.68)$ & $7.59(7.03,7.88)$ & NS \\
\hline $\begin{array}{l}\text { Weight gain (birth to } 12 \text { weeks PP; } \\
\mathrm{kg} / \text { day) }\end{array}$ & $0.03 \pm 0.01$ & $0.03 \pm 0.01$ & NS & $0.03 \pm 0.01$ & $0.03 \pm 0.01$ & NS & $0.03 \pm 0.01$ & $0.03 \pm 0.01$ & NS \\
\hline \multicolumn{10}{|c|}{ Total number of GMCD milestones attained in infants aged 12 weeks } \\
\hline Fine movement & $1.00(1.00,1.00)$ & $1.00(1.00,1.00)$ & NS & $1.00(1.00,1.00)$ & $1.00(1.00,1.00)$ & NS & $1.00(1.00,1.50)$ & $1.00(1.00,1.00)$ & NS \\
\hline Large movement & $4.00(4.00,4.00)$ & $4.00(3.00,4.00)$ & 0.03 & $4.00(4.00,4.00)$ & $4.00(3.00,4.00)$ & NS & $4.00(4.00,4.00)$ & $4.00(3.00,4.00)$ & NS \\
\hline Expressive language & $3.00(3.00,3.00)$ & $3.00(2.25,3.00)$ & NS & $3.00(3.00,3.00)$ & $3.00(2.75,3.00)$ & NS & $3.00(3.00,3.00)$ & $3.00(3.00,3.00)$ & NS \\
\hline Receptive language & $3.00(3.00,3.00)$ & $3.00(3.00,3.00)$ & NS & $3.00(3.00,3.00)$ & $3.00(3.00,3.00)$ & NS & $3.00(3.00,3.00)$ & $3.00(3.00,3.00)$ & NS \\
\hline Play activities & $2.00(2.00,2.00)$ & $2.00(1.00,2.00)$ & 0.02 & $2.00(2.00,2.00)$ & $2.00(1.00,2.00)$ & NS & $2.00(2.00,2.00)$ & $2.00(1.00,2.00)$ & NS \\
\hline Relating and response behaviour & $3.00(2.75,3.00)$ & $2.00(2.00,3.00)$ & NS & $3.00(2.25,3.00)$ & $2.00(2.00,3.00)$ & NS & $3.00(3.00,3.00)$ & $2.00(2.00,3.00)$ & NS \\
\hline
\end{tabular}


Data from mother-infant dyads that attended follow up are presented mean \pm SD or median (IQR) and $\mathrm{p}$ values are from adjusted multiple variable regression models. ${ }^{1}$ All infant anthropometric measures are standardised according to WHO child growth standards [21]. Differences in proportion of infants exclusively breastfed (EBF) at follow up were assessed by Fisher's exact test (2-tail). $\mathrm{PP}$ = postpartum; GMCD = Guide for monitoring child development. 
Supplementary table S5. Maternal nutrient intakes from one 24-hour dietary recall for mothers with and without HIV who attended follow up.

\begin{tabular}{|c|c|c|c|}
\hline & $\begin{array}{l}\text { HIV-uninfected } \\
\qquad(\mathrm{n}=10)\end{array}$ & $\begin{array}{l}\text { HIV-infected } \\
\quad(\mathrm{n}=21)\end{array}$ & $\mathrm{p}$ value \\
\hline \multicolumn{4}{|c|}{ Macronutrients - Absolute Intakes } \\
\hline Energy $(\mathrm{kJ})$ & $7339(3862-7984)$ & $5204(4024-6590)$ & NS \\
\hline Nitrogen $(g)$ & $4.15(2.26-6.29)$ & $6.67(4.87-8.20)$ & 0.02 \\
\hline Total protein $(\mathrm{g})$ & $46.6(23.7-57.6)$ & $44.0(33.2-61.6)$ & NS \\
\hline Plant protein $(\mathrm{g})$ & $26.0(13.2-40.5)$ & $18.9(12.5-25.4)$ & NS \\
\hline Animal protein $(\mathrm{g})$ & $13.8(3.3-33.5)$ & $27.5(18.6-35.0)$ & NS \\
\hline Total fat $(\mathrm{g})$ & $30.6(22.8-81.4)$ & $33.9(22.2-53.8)$ & NS \\
\hline Carbohydrate, avail. (g) & $201(140$ - 282) & $160(136-209)$ & NS \\
\hline Starch $(g)$ & $0.00(0-4.55)$ & $5.50(0.1-9.3)$ & 0.04 \\
\hline Glucose (g) & $0.20(0-5.8)$ & $3.70(1.8-4.55)$ & NS \\
\hline Fructose (g) & $0.20(0-7.35)$ & $6.10(0.65-6.8)$ & NS \\
\hline Galactose (g) & $0.00(0-0)$ & $0.00(0-0)$ & - \\
\hline Sucrose $(g)$ & $10.2(0-33.3)$ & $15.1(11.8-22.1)$ & NS \\
\hline Maltose (g) & $0.00(0-0)$ & $0.00(0-0)$ & - \\
\hline Lactose (g) & $0.00(0-3.38)$ & $0.00(0-0.2)$ & NS \\
\hline Total sugars (g) & $23.1(6.83-33.8)$ & $29.0(14.5-38.4)$ & NS \\
\hline Added sugar (g) & $6.35(0.53-67.0)$ & $13.4(10.6-26.05)$ & NS \\
\hline Non-starch polysaccharides (g) & $0.90(0-10.5)$ & $3.60(1.4-5.75)$ & NS \\
\hline Insoluble NSP (g) & $0.55(0-5.48)$ & $2.00(0.9-2.8)$ & NS \\
\hline Soluble NSP (g) & $0.35(0-4.48)$ & $1.50(0.55-2.6)$ & NS \\
\hline Lignin $(g)$ & $0.05(0-0.38)$ & $0.20(0.1-0.3)$ & NS \\
\hline Total dietary fibre (g) & $17.0(9.23-24.6)$ & $12.2(8.85-15.8)$ & NS \\
\hline Insoluble dietary fibre (g) & $0.60(0-6.1)$ & $2.30(0.95-3.2)$ & NS \\
\hline Soluble dietary fibre (g) & $0.35(0-4.48)$ & $1.50(0.55-2.6)$ & NS \\
\hline Ash $(g)$ & $7.75(3.8-13.8)$ & $6.10(4.6-12.5)$ & NS \\
\hline Moisture (g) & $623(340-1073)$ & $789(628-1030)$ & NS \\
\hline \multicolumn{4}{|l|}{ Minerals - Absolute Intakes } \\
\hline Ca (mg) & $195(106-382)$ & $132(85-187)$ & NS \\
\hline $\mathrm{Fe}(\mathrm{mg})$ & $11.3(6.98-13.5)$ & $10.9(7.4-12.5)$ & NS \\
\hline Haem iron (mg) & $0.05(0-0.63)$ & $0.40(0-0.55)$ & NS \\
\hline Non-haem iron (mg) & $1.95(0.15-4.55)$ & $3.30(2.25-4.25)$ & NS \\
\hline $\mathrm{Mg}(\mathrm{mg})$ & $280(116-347)$ & $168(135-224)$ & NS \\
\hline $\mathrm{P}(\mathrm{mg})$ & $723(418-855)$ & $573(420-731)$ & NS \\
\hline $\mathrm{K}(\mathrm{mg})$ & $1838(910-2858)$ & 1217 (925-1474) & NS \\
\hline $\mathrm{Na}(\mathrm{mg})$ & $2126(1009-3923)$ & $1608(1010-3360)$ & NS \\
\hline $\mathrm{Cl}(\mathrm{mg})$ & $96.5(30-406)$ & $397(245-567)$ & 0.02 \\
\hline $\mathrm{Zn}(\mathrm{mg})$ & $6.95(5.16-9.53)$ & $9.46(7.81-11.97)$ & NS \\
\hline $\mathrm{Cu}(\mathrm{mg})$ & $1.11(0.48-1.27)$ & $0.74(0.5-0.96)$ & NS \\
\hline
\end{tabular}




\begin{tabular}{|c|c|c|c|}
\hline $\mathrm{Cr}$ (mcg) & $10.4(0-47.03)$ & $31.00(25.3-49.8)$ & 0.05 \\
\hline Se (mcg) & $7.45(4.38-20.3)$ & $30.5(24.9-43.5)$ & $<.001$ \\
\hline Mn (mcg) & $1730(716-2414)$ & $991(801-1782)$ & NS \\
\hline I (mcg) & $91.0(25.3-168)$ & $92.0(63.5-189)$ & NS \\
\hline B (mcg) & $71.5(0-11)$ & 438 (169-624) & NS \\
\hline $\mathrm{F}(\mathrm{mcg})$ & $63.5(0.75-153)$ & $111(93-141)$ & NS \\
\hline $\mathrm{Si}(\mathrm{mcg})$ & $0.00(0-842)$ & $1776(284-3838)$ & 0.01 \\
\hline \multicolumn{4}{|c|}{ Vitamins - Absolute Intakes } \\
\hline Vitamin A (RE) (mcg) & $423(330-690)$ & $430(301-705)$ & NS \\
\hline Retinol (mcg) & $1.50(0-73.75)$ & $60.0(33-75.5)$ & NS \\
\hline Total carotenoids (mcg) & $745(0-3408)$ & $384(162-1434)$ & NS \\
\hline$\beta$-Carotene $(\mathrm{mcg})$ & $627(0-3368)$ & $281(156-1265)$ & NS \\
\hline$\alpha$-Carotene (mcg) & $0.00(0-36.3)$ & $104(0-123)$ & NS \\
\hline Cryptoxanthin (mcg) & $5.00(0-39.3)$ & $16.0(1-23.5)$ & NS \\
\hline Thiamin (mg) & $1.06(0.64-1.40)$ & $1.08(0.69-1.41)$ & NS \\
\hline Riboflavin (mg) & $0.51(0.32-1.26)$ & $0.76(0.65-0.97)$ & NS \\
\hline Niacin (mg) & $14.6(9.03-20.28)$ & $16.3(9.8-19.6)$ & NS \\
\hline Vitamin B6 (mg) & $2.36(1.37-5.19)$ & $3.13(1.66-3.723)$ & NS \\
\hline Folate (mcg) & $212(180-383)$ & $278(207-312)$ & NS \\
\hline Vitamin B12 (mcg) & $1.65(0.23-2.45)$ & $1.80(1.6-3.2)$ & NS \\
\hline Pantothenate (mg) & $2.33(2.08-3.02)$ & $2.95(2.27-4.82)$ & NS \\
\hline Biotin (mcg) & $14.5(10.1-27.8)$ & $25.4(20.8-34.7)$ & NS \\
\hline Vitamin C (mg) & $31.5(2.25-91.5)$ & $22.0(10.5-62.5)$ & NS \\
\hline Vitamin D (mcg) & $0.86(0.04-2.08)$ & $6.45(4.20-8.46)$ & 0.002 \\
\hline Vitamin E (mg) & $5.24(3.32-11.7)$ & $7.91(4.73-13.3)$ & NS \\
\hline$\alpha$-Tocopherol (mg) & $0.38(0-3.72)$ & $6.08(3.44-8.67)$ & 0.005 \\
\hline$\beta$-Tocopherol (mg) & $0.00(0-0.11)$ & $0.20(0.12-0.31)$ & 0.002 \\
\hline$\delta$-Tocopherol (mg) & $0.00(0-0.02)$ & $0.11(0.11-0.22)$ & $<.001$ \\
\hline$\gamma$-Tocopherol (mg) & $0.00(0-0.21)$ & $0.49(0.45-0.83)$ & 0.004 \\
\hline$\alpha$-Tocotrienol (mg) & $0.00(0-0.06)$ & $0.07(0.07-0.15)$ & 0.005 \\
\hline$\beta$-Tocotrienol (mg) & $0.00(0-0.02)$ & $0.05(0.03-0.06)$ & 0.005 \\
\hline$\delta$-Tocotrienol (mg) & $0.00(0-0)$ & $0.00(0-0)$ & - \\
\hline$\gamma$-Tocotrienol (mg) & $0.00(0-0.02)$ & $0.01(0-0.02)$ & NS \\
\hline Lycopene (mcg) & $0.00(0-133)$ & $0.00(0-2.5)$ & NS \\
\hline Lutein (mcg) & $38.0(0-7900)$ & $51.0(9-140)$ & NS \\
\hline Vitamin K (mcg) & $23.8(0.05-403)$ & $19.8(8.9-57.2)$ & NS \\
\hline \multicolumn{4}{|c|}{ Fatty Acids (FA) and Cholesterol - Absolute Intakes } \\
\hline Saturated FA (g) & $9.31(5.67-14.9)$ & $8.95(6.34-13.2)$ & NS \\
\hline Mono-unsaturated FA (g) & $11.8(7.01-19.6)$ & $11.8(7.90-16.4)$ & NS \\
\hline Polyunsaturated FA (g) & $6.74(2.74-37.4)$ & $7.15(5.36-16.0)$ & NS \\
\hline Single trans FA $(\mathrm{g})$ & $0.00(0-0)$ & $0.00(0-0)$ & - \\
\hline Double trans FA (g) & $0.00(0-0)$ & $0.00(0-0)$ & - \\
\hline
\end{tabular}




\begin{tabular}{|c|c|c|c|}
\hline Total trans FA (g) & $0.13(0-1.27)$ & $0.19(0.03-0.34)$ & NS \\
\hline Cholesterol (mg) & $65.5(30-130)$ & $324(259-461)$ & $<.0001$ \\
\hline C4:0 (g) & $0.00(0-0.11)$ & $0.00(0-0)$ & NS \\
\hline C6:0 (g) & $0.00(0-0.07)$ & $0.00(0-0)$ & NS \\
\hline C8:0 (g) & $0.00(0-0.04)$ & $0.00(0-0.02)$ & NS \\
\hline C10:0 (g) & $0.01(0-0.09)$ & $0.02(0-0.05)$ & NS \\
\hline $\mathrm{C} 12: 0(\mathrm{~g})$ & $0.04(0.01-0.21)$ & $0.04(0.01-0.13)$ & NS \\
\hline $\mathrm{C} 13: 0(\mathrm{~g})$ & $0.00(0-0)$ & $0.00(0-0)$ & - \\
\hline $\mathrm{C} 14: 0(\mathrm{~g})$ & $0.36(0.06-0.94)$ & $0.27(0.18-0.45)$ & NS \\
\hline C15:0 (g) & $0.00(0-0)$ & $0.02(0.01-0.02)$ & $<.001$ \\
\hline C16:0 (g) & $5.10(3.04-8.57)$ & $4.81(3.68-7.16)$ & NS \\
\hline $\mathrm{C} 17: 0(\mathrm{~g})$ & $0.00(0-0.01)$ & $0.01(0-0.01)$ & NS \\
\hline C18:0 (g) & $2.25(1.36-3.23)$ & $2.25(1.9-3.72)$ & NS \\
\hline C20:0 (g) & $0.09(0.02-0.20)$ & $0.05(0.02-0.1)$ & NS \\
\hline C21:0 (g) & $0.00(0-0)$ & $0.00(0-0)$ & - \\
\hline C22:0 (g) & $0.05(0-0.25)$ & $0.04(0.02-0.15)$ & NS \\
\hline C23:0 (g) & $0.00(0-0)$ & $0.00(0-0)$ & - \\
\hline C24:0 (g) & $0.02(0-0.10)$ & $0.04(0.02-0.10)$ & NS \\
\hline C10:1 (g) & $0.00(0-0)$ & $0.00(0-0)$ & - \\
\hline C12:1 (g) & $0.00(0-0)$ & $0.00(0-0)$ & - \\
\hline C14:1 (g) & $0.00(0-0.04)$ & $0.01(0-0.02)$ & NS \\
\hline $\mathrm{C} 15: 1(\mathrm{~g})$ & $0.00(0-0)$ & $0.00(0-0)$ & - \\
\hline C16:1 (g) & $0.33(0.19-0.53)$ & $0.60(0.48-0.97)$ & 0.01 \\
\hline C17:1 (g) & $0.00(0-0)$ & $0.00(0-0)$ & NS \\
\hline C18:1 (g) & $10.49(5.57-18.4)$ & $10.09(6.54-14.5)$ & NS \\
\hline C20:1 (g) & $0.10(0.03-0.25)$ & $0.04(0.02-0.11)$ & NS \\
\hline C22:1 (g) & $0.04(0-0.21)$ & $0.00(0-0.03)$ & NS \\
\hline C23:1 (g) & $0.00(0-0)$ & $0.00(0-0)$ & - \\
\hline C24:1 (g) & $0.00(0-0)$ & $0.00(0-0)$ & - \\
\hline C18:2 (g) & $5.71(1.42-35.7)$ & $5.54(4.09-12.3)$ & NS \\
\hline $\mathrm{C} 18: 3(\mathrm{~g})$ & $0.26(0.11-0.99)$ & $0.21(0.14-0.4)$ & NS \\
\hline C18:4 (g) & $0.00(0-0.005)$ & $0.00(0-0)$ & NS \\
\hline $\mathrm{C} 20: 2(\mathrm{~g})$ & $0.00(0-0.01)$ & $0.04(0.03-0.06)$ & 0.001 \\
\hline C20:4 (g) & $0.04(0-0.07)$ & $0.07(0.04-0.1)$ & NS \\
\hline C20:5 (g) & $0.02(0-0.04)$ & $0.03(0.02-0.04)$ & NS \\
\hline $\mathrm{C} 22: 2(\mathrm{~g})$ & $0.00(0-0.003)$ & $0.01(0-0.01)$ & 0.03 \\
\hline $\mathrm{C} 22: 3(\mathrm{~g})$ & $0.00(0-0)$ & $0.00(0-0)$ & - \\
\hline C22:4 (g) & $0.00(0-0)$ & $0.00(0-0)$ & - \\
\hline $\mathrm{C} 22: 5(\mathrm{~g})$ & $0.00(0-0.01)$ & $0.00(0-0.01)$ & NS \\
\hline $\mathrm{C} 22: 6(\mathrm{~g})$ & $0.03(0-0.07)$ & $0.07(0.04-0.08)$ & NS \\
\hline C24:6 (g) & $0.00(0-0)$ & $0.00(0-0)$ & - \\
\hline C20:3 (g) & $0.00(0-0.01)$ & $0.00(0-0.01)$ & NS \\
\hline
\end{tabular}




\begin{tabular}{|c|c|c|c|}
\hline \multicolumn{4}{|l|}{ Amino Acids - Absolute Intakes } \\
\hline Isoleucine (g) & $1.46(0.74-2.10)$ & $1.41(1.16-2.16)$ & NS \\
\hline Leucine $(\mathrm{g})$ & $2.76(1.38-4.08)$ & $2.78(2.14-3.88)$ & NS \\
\hline Lysine (g) & $1.72(0.98-2.90)$ & $2.46(1.55-3.195)$ & NS \\
\hline Methionine (g) & $0.83(0.41-0.96)$ & $0.92(0.65-1.19)$ & NS \\
\hline Phenylalanine (g) & $1.59(0.79-2.39)$ & $1.59(1.21-2.36)$ & NS \\
\hline Threonine (g) & $1.31(0.70-1.92)$ & $1.43(1.07-1.98)$ & NS \\
\hline Tryptophan (g) & $0.46(0.27-0.63)$ & $0.54(0.38-0.71)$ & NS \\
\hline Valine $(\mathrm{g})$ & $1.72(0.85-2.47)$ & $1.68(1.36-2.49)$ & NS \\
\hline Arginine (g) & $1.69(1.13-2.83)$ & $2.23(1.53-3.27)$ & NS \\
\hline Histidine (g) & $0.88(0.41-1.24)$ & $0.93(0.73-1.29)$ & NS \\
\hline Cystine (g) & $0.33(0.20-0.48)$ & $0.64(0.53-0.81)$ & $<.001$ \\
\hline Tyrosine (g) & $0.69(0.29-1.02)$ & $1.06(0.73-1.40)$ & 0.03 \\
\hline Alanine (g) & $0.85(0.35-1.60)$ & $1.59(1.11-2.23)$ & 0.02 \\
\hline Aspartic acid (g) & $1.45(0.80-2.69)$ & $2.90(1.78-3.53)$ & 0.04 \\
\hline Glutamic acid (g) & $4.76(3.04-5.91)$ & $5.50(3.31-8.31)$ & NS \\
\hline Glycine (g) & $0.73(0.36-1.44)$ & $1.33(0.93-2.00)$ & 0.03 \\
\hline Proline (g) & $1.43(0.89-2.01)$ & $1.74(1.09-2.58)$ & NS \\
\hline Serine $(g)$ & $0.98(0.46-1.59)$ & $1.65(1.33-2.02)$ & 0.01 \\
\hline Hydroxyproline (g) & $0.02(0-0.18)$ & $0.09(0-0.17)$ & NS \\
\hline Alcohol (g) & $0.00(0-0)$ & $0.00(0-0)$ & - \\
\hline Phytate (mg) & $155(6-192)$ & $192(99.5-225)$ & NS \\
\hline Malic acid (mg) & $38.0(0-879)$ & $305(14.5-612.5)$ & NS \\
\hline Citric acid (mg) & $276.50(0-1275)$ & $221(77-508)$ & NS \\
\hline Tartaric acid (mg) & $0.00(0-0)$ & $0.00(0-0)$ & NS \\
\hline Oxalic acid (mg) & $6.00(0-384)$ & $11.0(0-37.5)$ & NS \\
\hline Caffeine (mg) & $0.00(0-0)$ & $0.00(0-0)$ & - \\
\hline Tannins (mg) & $0.00(0-0)$ & $0.00(0-0)$ & - \\
\hline \multicolumn{4}{|l|}{ Energy - \% } \\
\hline \% Energy - Protein & $0.13(0.08-0.18)$ & $0.15(0.13-0.18)$ & NS \\
\hline \% Energy - Fat & $0.20(0.13-0.40)$ & $0.25(0.21-0.31)$ & NS \\
\hline \% Energy - Saturated SFA & $0.06(0.04-0.07)$ & $0.06(0.05-0.09)$ & NS \\
\hline \% Energy - Mono-unsaturated FA & $0.07(0.05-0.12)$ & $0.09(0.08-0.11)$ & NS \\
\hline \% Energy - Polyunsaturated FA & $0.04(0.02-0.16)$ & $0.06(0.04-0.09)$ & NS \\
\hline \% Energy - Carbohydrate & $0.64(0.52-0.70)$ & $0.59(0.51-0.65)$ & NS \\
\hline
\end{tabular}


Supplementary table S6. Maternal nutrient intake from one 24-hour dietary recall for mothers who report experiencing food insecurity compared to those who do not experience food insecurity.

\section{Do you experience food runout? \\ Are you able to afford balanced meals?}

\begin{tabular}{|c|c|c|c|c|c|c|}
\hline & NO & YES & \multirow{2}{*}{$p$ value } & YES & NO & \multirow{2}{*}{$\mathrm{p}$ value } \\
\hline & $\mathrm{n}=16$ & $\mathrm{n}=15$ & & $\mathrm{n}=9$ & $\mathrm{n}=22$ & \\
\hline Dietary diversity score (/9) & $5.00(4.00,6.00)$ & $3.00(4.00,5.00)$ & NS & $4.00(3.50,5.50)$ & $4.00(3.75,6.00)$ & NS \\
\hline Dietary diversity score $<4$ (n) & 2 & 5 & NS & 2 & 5 & NS \\
\hline
\end{tabular}

\begin{tabular}{|c|c|c|c|c|c|c|}
\hline \multicolumn{7}{|l|}{ Absolute intakes } \\
\hline \multicolumn{7}{|l|}{ Macronutrients } \\
\hline Moisture (g) & $868(620,1030)$ & $670(409,1011)$ & NS & $789(614,1037)$ & $806(564,1016)$ & NS \\
\hline Energy (kJ) & $5601(4659,7004)$ & $5204(3247,8339)$ & NS & $5691(4519,7046)$ & $5358(3538,7505)$ & NS \\
\hline Nitrogen (g) & $7.15(5.68,9.29)$ & $4.31(3.87,6.10)$ & 0.02 & $6.94(5.00,9.53)$ & $5.52(4.03,7.37)$ & NS \\
\hline Total protein $(\mathrm{g})$ & $51.4(42.5,68.7)$ & $32.9(26.1,44.7)$ & 0.03 & $53.3(41.5,67.7)$ & $40.9(27.5,54.6)$ & NS \\
\hline Plant protein (g) & $19.6(15.8,27.3)$ & $22.3(11.5,34.9)$ & NS & $19.9(17.0,33.1)$ & $20.6(11.6,34.0)$ & NS \\
\hline Animal protein $(\mathrm{g})$ & $29.0(19.7,38.0)$ & $15.4(3.30,21.4)$ & 0.01 & $28.5(19.0,38.5)$ & $18.9(9.65,33.2)$ & NS \\
\hline Total fat (g) & $35.0(29.9,45.8)$ & $25.8(19.6,69.0)$ & NS & $37.5(25.1,57.2)$ & $31.0(21.9,63.1)$ & NS \\
\hline Carbohydrates, avail. (g) & $162(159,234)$ & $161(93.8,280)$ & NS & $165(158,229)$ & $160(106,259)$ & NS \\
\hline Starch $(g)$ & $5.60(0.13,10.1)$ & $0.00(0.00,5.40)$ & NS & $5.60(0.05,6.80)$ & $0.20(0.00,12.5)$ & NS \\
\hline Glucose (g) & $3.95(2.75,5.60)$ & $1.20(0.00,3.40)$ & 0.01 & $3.80(2.50,5.25)$ & $2.55(0.30,4.55)$ & NS \\
\hline Fructose (g) & $6.50(1.20,8.15)$ & $0.40(0.00,6.10)$ & 0.01 & $6.50(1.90,7.75)$ & $1.10(0.00,6.65)$ & NS \\
\hline Sucrose (g) & $19.1(12.4,30.1)$ & $8.40(1.00,17.9)$ & 0.03 & $20.4(16.3,28.1)$ & $12.0(3.98,23.9)$ & NS \\
\hline Maltose $(\mathrm{g})^{1}$ & & 0.1 & & & 0.1 & \\
\hline \multicolumn{7}{|l|}{ Galactose $^{2}$} \\
\hline Lactose (g) & $0.00(0.00,1.60)$ & $0.00(0.00,0.10)$ & NS & $0.00(0.00,2.40)$ & $0.00(0.00,0.15)$ & NS \\
\hline Total sugars (g) & $31.2(24.3,42.5)$ & $13.1(7.00,30.9)$ & 0.02 & $32.0(29.6,39.5)$ & $20.8(9.10,37.1)$ & NS \\
\hline Added sugar (g) & $17.6(12.0,40.5)$ & $8.00(0.30,21.0)$ & 0.04 & $13.4(10.5,25.6)$ & $12.0(3.70,39.5)$ & NS \\
\hline Total dietary fibre (g) & $13.4(10.9,17.2)$ & $12.2(6.20,18.4)$ & NS & $14.5(11.6,16.3)$ & $12.3(8.10,17.9)$ & NS \\
\hline
\end{tabular}




\begin{tabular}{|c|c|c|c|c|c|c|}
\hline Insoluble dietary fibre (g) & $3.15(1.68,4.08)$ & $1.20(0.00,3.20)$ & 0.04 & $3.10(1.35,3.90)$ & $1.75(0.00,3.33)$ & NS \\
\hline Soluble dietary fibre (g) & $2.20(1.30,2.70)$ & $0.70(0.00,2.90)$ & NS & $2.20(0.85,2.75)$ & $1.30(0.00,2.75)$ & NS \\
\hline Ash (g) & $6.05(4.55,6.58)$ & $10.5(4.20,14.8)$ & NS & $6.10(4.25,6.55)$ & $6.15(4.63,14.6)$ & NS \\
\hline Non-starch polysaccharides (g) & $4.85(2.68,6.33)$ & $1.80(0.00,5.90)$ & NS & $4.90(2.00,6.25)$ & $2.75(0.00,6.05)$ & NS \\
\hline Insoluble NSP (g) & $2.60(1.43,3.50)$ & $1.10(0.00,2.80)$ & NS & $2.50(1.05,3.30)$ & $1.45(0.00,2.98)$ & NS \\
\hline Soluble NSP (g) & $2.20(1.30,2.70)$ & $0.70(0.00,2.90)$ & NS & $2.20(0.85,2.75)$ & $0.00(1.30,2.75)$ & NS \\
\hline Lignin $(g)$ & $0.25(0.13,0.38)$ & $0.00(0.00,0.20)$ & 0.01 & $0.30(0.20,0.40)$ & $0.10(0.00,0.23)$ & NS \\
\hline \multicolumn{7}{|l|}{ Amino acids } \\
\hline Isoleucine (g) & $1.78(1.38,2.43)$ & $1.08(0.79,1.47)$ & 0.05 & $1.77(1.26,2.55)$ & $1.50(0.89,1.95)$ & NS \\
\hline Leucine $(\mathrm{g})$ & $3.48(2.77,4.47)$ & $1.95(1.47,2.75)$ & 0.03 & $3.36(2.60,2.46)$ & $2.47(1.58,3.71)$ & NS \\
\hline lysine (g) & $2.59(1.99,3.80)$ & $1.23(1.03,2.57)$ & 0.03 & $2.71(1.81,4.05)$ & $1.74(1.06,2.65)$ & NS \\
\hline Methionine (g) & $0.96(0.88,1.13)$ & $0.61(0.45,0.85)$ & 0.002 & $1.06(0.93,2.44)$ & $1.01(0.78,1.64)$ & NS \\
\hline Phenylalanine (g) & $2.01(1.55,2.51)$ & $1.22(0.80,1.69)$ & 0.04 & $1.96(1.42,2.43)$ & $1.51(1.00,2.22)$ & NS \\
\hline Threonine (g) & $1.73(1.38,2.22)$ & $0.95(0.74,1.43)$ & 0.02 & $1.69(1.26,2.23)$ & $1.25(0.79,1.81)$ & NS \\
\hline Tryptophan (g) & $0.61(0.53,0.76)$ & $0.34(0.30,0.51)$ & 0.003 & $0.59(0.48,0.77)$ & $0.42(0.31,0.63)$ & NS \\
\hline Valine $(\mathrm{g})$ & $2.12(1.68,2.56)$ & $1.24(0.87,1.75)$ & 0.04 & $2.01(1.53,2.58)$ & $1.57(1.12,2.38)$ & NS \\
\hline Arginine (g) & $2.53(1.96,3.57)$ & $1.48(1.17,2.12)$ & 0.03 & $2.44(1.79,3.49)$ & $1.80(1.28,2.68)$ & NS \\
\hline Histidine (g) & $1.14(0.89,1.51)$ & $0.64(0.42,1.26)$ & 0.01 & $1.16(0.82,1.51)$ & $0.76(0.50,1.20)$ & NS \\
\hline Cystine (g) & $0.62(0.52,0.81)$ & $0.48(0.30,0.62)$ & 0.02 & $0.60(0.48,0.78)$ & $0.52(0.34,0.72)$ & NS \\
\hline Tyrosine (g) & $1.14(0.94,1.42)$ & $0.75(0.46,0.90)$ & 0.03 & $1.09(0.80,1.40)$ & $0.85(0.49,1.10)$ & NS \\
\hline Alanine (g) & $1.75(1.37,2.29)$ & $0.92(0.66,1.46)$ & 0.006 & $1.76(1.20,2.32)$ & $1.24(0.73,1.73)$ & NS \\
\hline Aspartic acid (g) & $3.01(2.46,3.74)$ & $1.47(1.04,2.90)$ & 0.04 & $2.93(2.06,3.90)$ & $1.87(1.30,3.02)$ & NS \\
\hline Glutamic acid (g) & $5.85(5.25,8.12)$ & $4.33(1.70,5.78)$ & NS & $5.71(4.26,7.54)$ & $4.58(2.39,6.46)$ & NS \\
\hline Glycine (g) & $1.52(1.13,2.14)$ & $0.84(0.42,1.30)$ & 0.009 & $1.49(1.06,2.13)$ & $1.04(0.63,1.48)$ & NS \\
\hline Proline (g) & $1.85(1.58,2.59)$ & $1.28(0.51,1.92)$ & 0.03 & $1.81(1.36,2.35)$ & $1.38(0.78,2.36)$ & NS \\
\hline Serine $(g)$ & $1.68(1.52,2.02)$ & $1.09(0.85,1.48)$ & 0.01 & $1.65(1.29,2.02)$ & $1.43(0.91,1.71)$ & NS \\
\hline Hydroxyproline (g) & $0.11(0.06,0.26)$ & $0.00(0.00,0.07)$ & 0.005 & $0.11(0.07,0.24)$ & $0.00(0.00,0.11)$ & 0.04 \\
\hline \multicolumn{7}{|l|}{ Fatty acids and cholesterol } \\
\hline Saturated FA (g) & $9.68(8.88,14.7)$ & $6.80(5.69,12.9)$ & 0.03 & $9.77(8.33,19.5)$ & $7.96(5.98,12.1)$ & NS \\
\hline
\end{tabular}




\begin{tabular}{|c|c|c|c|c|c|c|}
\hline Mono-unsaturated FA (g) & $11.7(10.4,15.0)$ & $12.0(6.86,25.7)$ & NS & $11.8(8.26,16.4)$ & $11.5(7.6,21.8)$ & NS \\
\hline Polyunsaturated FA (g) & $7.67(5.87,13.9)$ & $5.47(3.88,22.7)$ & NS & $9.40(4.85,15.5)$ & $6.34(4.49,18.4)$ & NS \\
\hline \multicolumn{7}{|l|}{ Single trans FA $(\mathrm{g})^{2}$} \\
\hline \multicolumn{7}{|l|}{ Double trans FA $(\mathrm{g})^{2}$} \\
\hline Total trans FA (g) & $0.21(0.16,0.75)$ & $0.04(0.00,0.20)$ & 0.03 & $0.73(0.16,1.00)$ & $0.06(0.00,0.21)$ & 0.03 \\
\hline Cholesterol (mg) & $291(191,524)$ & $112(26.0,416)$ & 0.03 & $269(213,326)$ & $261(45.5,446)$ & NS \\
\hline \multicolumn{7}{|c|}{ Median intake (\%) of TULs by mothers } \\
\hline \multicolumn{7}{|c|}{ Minerals } \\
\hline Calcium (Ca) & $5.88(4.56,9.90)$ & $4.52(2.72,9.56)$ & NS & $7.04(4.90,11.7)$ & $4.76(3.01,8.33)$ & NS \\
\hline Iron $(\mathrm{Fe})$ & $25.6(21.0,27.4)$ & $18.2(12.0,30.2)$ & NS & $25.8(213,30.0)$ & $24.2(14.6,28.3)$ & NS \\
\hline Magnesium (Mg) & $52.1(43.1,74.6)$ & $57.1(30.3,95.1)$ & NS & $54.0(46.4,78.7)$ & $52.1(30.7,88.6)$ & NS \\
\hline Phosphorus $(\mathrm{P})$ & $16.7(12.8,20.7)$ & $12.1(8.65,18.5)$ & NS & $15.2(12.9,21.2)$ & $14.6(9.83,18.9)$ & NS \\
\hline Sodium $(\mathrm{Na})$ & $61.9(47.6,84.9)$ & $132(51.2,221)$ & NS & $65.1(48.4,95.0)$ & $73.6(45.0,181)$ & NS \\
\hline Zinc $(\mathrm{Zn})$ & $23.3(20.2,30.3)$ & $17.7(14.4,24.2)$ & NS & $20.9(20.2,36.8)$ & $21.0(15.2,26.6)$ & NS \\
\hline Copper $(\mathrm{Cu})$ & $8.15(6.43,11.7)$ & $6.90(3.90,11.0)$ & NS & $8.60(6.30,10.7)$ & $7.15(4.45,11.4)$ & NS \\
\hline Selenium (Se) & $7.63(5.91,11.2)$ & $5.58(1.80,7.78)$ & NS & $7.50(6.03,8.66)$ & $6.45(2.73,9.89)$ & NS \\
\hline Manganese (Mn) & $12.8(8.77,19.3)$ & $12.7(5.36,16.7)$ & NS & $14.7(8.84,27.1)$ & $11.5(6.52,16.9)$ & NS \\
\hline Iodine (I) & $7.67(3.73,11.2)$ & $14.0(5.09,19.6)$ & NS & $8.18(3.59,13.6)$ & $8.36(4.84,18.4)$ & NS \\
\hline \multicolumn{7}{|l|}{ Vitamins } \\
\hline Vitamin A & $14.2(10.5,20.9)$ & $14.1(8.54,25.2)$ & NS & $12.2(10.2,16.1)$ & $14.7(8.95,24.9)$ & NS \\
\hline Niacin & $47.4(41.4,55.9)$ & $40.0(23.4,55.7)$ & NS & $46.6(41.7,54.0)$ & $42.1(24.9,58.1)$ & NS \\
\hline Vitamin B6 & $3.20(2.72,3.89)$ & $1.89(1.16,3.80)$ & NS & $3.26(2.80,5.09)$ & $2.61(1.37,3.69)$ & NS \\
\hline Folate & $27.8(20.0,30.1)$ & $24.1(20.5,47.6)$ & NS & $27.8(22.6,29.9)$ & $25.0(19.3,37.1)$ & NS \\
\hline Vitamin C & $1.34(0.99,2.55)$ & $0.55(0.00,6.25)$ & NS & $2.40(0.85,3.90)$ & $1.13(0.23,3.59)$ & NS \\
\hline Vitamin D & $4.73(4.14,8.60)$ & $1.39(0.05,7.86)$ & NS & $4.72(4.20,6.22)$ & $4.12(0.72,8.06)$ & NS \\
\hline Vitamin E & $0.73(0.49,1.16)$ & $0.68(0.39,1.46)$ & NS & $0.80(0.51,1.13)$ & $0.62(0.42,1.50)$ & NS \\
\hline
\end{tabular}

Data from mother-infant dyads that attended follow up are presented as mean \pm SD or median (IQR) and p values are from univariate analysis (KruskalWallis/Wilcoxon test for non-parametric data; ANOVA for normal data with equal variance). Dietary diversity score was calculated using nine food groups, only counting each food groups once (refs). Percent intake of TULs were calculated using the Institute of Medicine's TULs for minerals and vitamins for 
lactating women 14-18, 19-30 or 31-50 years of age [26]. Iodised salt was assumed to be consumed by all mothers, as the majority of salt consumed in South Africa is iodised [64].TULs $=$ Tolerable upper levels. ${ }^{1}$ Only one mother consumed maltose. ${ }^{2}$ None consumed by mothers. 